\title{
Regulation of Glucose and Lipid Metabolism by Long Non-coding RNAs: Facts and Research Progress
}

\author{
Tie-Ning Zhang ${ }^{1 *}$, Wei Wang ${ }^{1}$, Ni Yang ${ }^{1}$, Xin-Mei Huang ${ }^{2,3 *}$ and Chun-Feng Liu ${ }^{1 *}$ \\ ${ }^{1}$ Department of Pediatrics, Shengjing Hospital of China Medical University, Shenyang, China, ${ }^{2}$ Department of Endocrinology, \\ the Fifth People's Hospital of Shanghai, Fudan University, Shanghai, China, ${ }^{3}$ Department of Obstetrics and Gynecology, Yale \\ University School of Medicine, New Haven, CT, United States
}

OPEN ACCESS

Edited by:

Marcus M. Seldin, University of California, Irvine,

United States

Reviewed by:

Xu Zhang,

Jiangsu University, China

Deeksha Bhartiya,

Karolinska Institutet (KI), Sweden

*Correspondence:

Tie-Ning Zhang

cmuztn@vip.qq.com

Xin-Mei Huang

xinmei.huang@yale.edu

Chun-Feng Liu

zhliu258@hotmail.com

Specialty section:

This article was submitted to

Systems Endocrinology,

a section of the journal

Frontiers in Endocrinology

Received: 11 March 2020

Accepted: 10 June 2020

Published: 16 July 2020

Citation:

Zhang T-N, Wang W, Yang N, Huang X-M and Liu C-F (2020)

Regulation of Glucose and Lipid Metabolism by Long Non-coding RNAs: Facts and Research Progress.

Front. Endocrinol. 11:457. doi: 10.3389/fendo.2020.00457
Long non-coding RNAs (IncRNAs) are a type of non-coding RNA with a length that exceeds 200 nucleotides. Previous studies have shown that IncRNAs play an important role in the pathogenesis of various diseases. Research in both animal models and humans has begun to unravel the profound complexity of IncRNAs and demonstrated that IncRNAs exert direct effects on glucose and lipid metabolism both in vivo and in vitro. Such research has elucidated the regulatory role of IncRNAs in glucose and lipid metabolism in human disease. IncRNAs mediate glucose and lipid metabolism under physiological and pathological conditions and contribute to various metabolism disorders. This review provides an update on our understanding of the regulatory role of IncRNAs in glucose and lipid metabolism in various diseases. As our understanding of the function of IncRNAs improves, the future is promising for the development of new diagnostic biomarkers that utilize IncRNAs and treatments that target IncRNAs to improve clinical outcomes.

Keywords: IncRNA, glucose metabolism, lipid metabolism, regulatory role, tissue, cancer

\section{INTRODUCTION}

Only $1-2 \%$ of the mammalian genome is translated into proteins. Many more non-coding RNAs reside in the genome, and most of them have unknown functions (1). Long non-coding RNAs (lncRNAs) are a special type of non-coding RNA with a length that exceeds 200 nucleotides. Abundant studies have indicated that lncRNAs can have different expression patterns in disease states $(2,3)$. Notably, lncRNAs have been shown to mediate various biological processes in cells, including glucose and lipid metabolism $(4,5)$.

Glucose is the major carbon source for cellular biosynthesis and energy generation (6). Normal glucose metabolism is essential for cell life and influences cell survival. Glucose metabolism occurs through the glycolysis pathway, pentose phosphate pathway, and serine synthesis pathway in the cytoplasm and tricarboxylic acid cycle in mitochondria. Cells are well-known to acquire energy via glycolysis in the cytosol, followed by mitochondrial oxidative phosphorylation under aerobic conditions (7). When oxygen is scarce, cells rely on glycolysis rather than oxygenconsuming mitochondrial metabolism for an energy supply (7). Glucose metabolic reprogramming is widely observed during different disease states. For example, cancer cells preferentially perform glycolysis in the cytosol even in the presence of oxygen, a phenomenon that is known as the "Warburg effect" or "aerobic glycolysis." Glucose metabolism is also related to lipid metabolism. Lipid metabolism refers to the synthesis and degradation of lipids in cells and involves the breakdown or storage of fats for energy and the synthesis of structural and functional lipids. 
Aberrant lipid metabolism is associated with higher concentrations of plasma lipids, including low-density lipoprotein (LDL), cholesterol, very-low-density lipoprotein, and triglycerides, and involved in such diseases as atherosclerosis (8). The regulatory network of glucose and lipid metabolism is complex. A firm understanding of the regulation of metabolism may be key to inducing alterations of the process and improve the prognosis of various types of diseases. Substantial studies have explored the regulatory process of glucose and lipid metabolism from the perspective of lncRNAs in an effort to provide new insights into the regulatory mechanism of glucose and lipid metabolism.

To enhance our understanding of lncRNAs in glucose and lipid metabolism, a comprehensive summary of the role of lncRNAs in glucose and lipid metabolism is needed. The present review provides an update on IncRNA-mediated metabolism and highlights the role of lncRNAs in various diseases that involve glucose and lipid metabolism.

\section{OVERVIEW OF LncRNAS}

lncRNAs are found in every branch of life, displaying a high degree of tissue- and cell-specific distribution (9). IncRNAs can be categorized into intergenic, intronic, bidirectional, sense, and antisense lncRNAs, depending on their genomic position relative to nearby protein-coding genes (10, 11). Notably, large intergenic non-coding RNA (lincRNAs) are transcribed from intergenic regions by RNA polymerase II; hence, they are presumably capped, polyadenylated, and spliced exactly as mRNAs (12). To date, lincRNAs are the most abundant type of lncRNAs.

Functionally, lncRNAs contribute to transcriptional and post-transcriptional functions and can be broadly classified as signaling, decoy, guide, or scaffold molecules (Figure 1) (13). IncRNAs participate in regulating gene expression by interacting with proteins, RNAs, and DNAs through various mechanisms. Interestingly, the functions of lncRNAs have been shown to be associated with their unique subcellular localization (14). Many lncRNAs are recognized as nuclear modulators and have distinct nuclear localization patterns. One group of nuclear lncRNAs, lncRNA CCAT1-L, accumulates at their sites of transcription and regulate adjacent gene expression in cis by recruiting transcription factors, chromatin organizers, and chromatin modifiers or by forming a DNA-RNA-protein triplex $(14,15)$. IncRNAs that are localized in cis, including snolncRNAs, can also modulate gene expression in trans by acting as decoys to sequester RNA-binding proteins (RBPs) (16). Another group of lncRNAs relocates from their sites of transcription to exert functions on gene regulation in trans via the epigenetic control of transcription, recruiting chromatin modifiers to target

\section{guide}

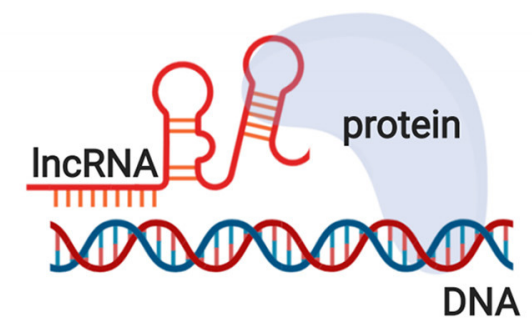

decoy

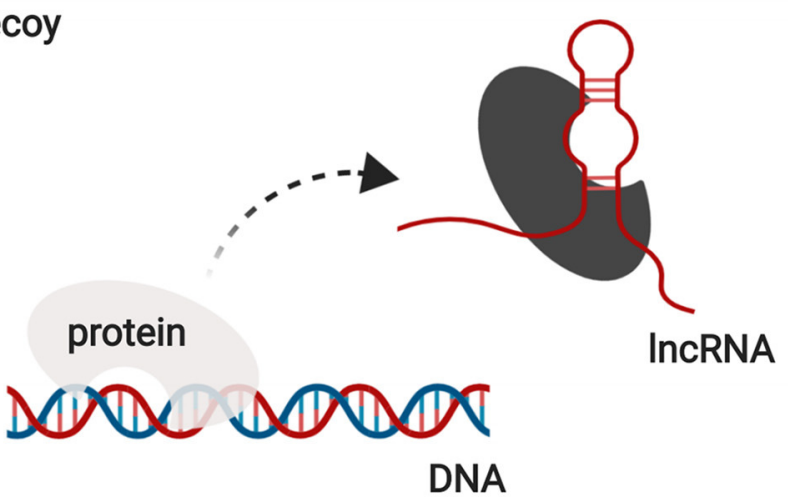

scaffold

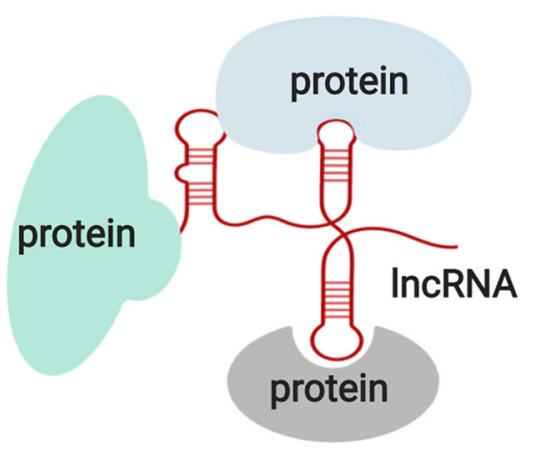

signal

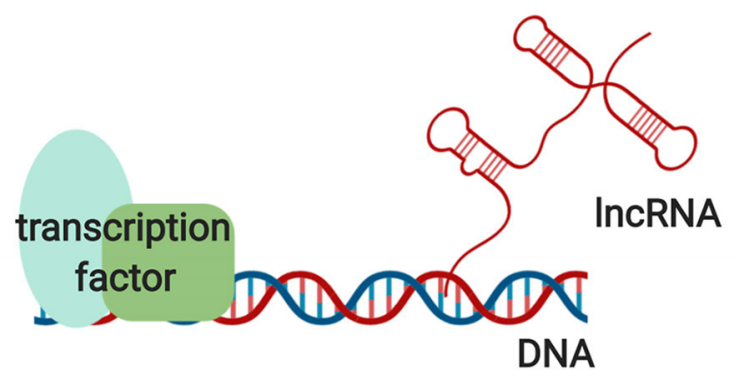

FIGURE 1 | The action of IncRNAs via various mechanisms. 
genes or acting as decoys for RBPs. HOX transcript antisense RNA (HOTAIR) is one of the best examples of this group of lncRNAs (17). In addition to nuclear lncRNAs, other lncRNAs need to be exported into the cytoplasm to perform their functions. Abundant research has illustrated that cytoplasmic lncRNAs regulate gene expression by modulating signaling pathways, acting as microRNA and protein decoys, acting as scaffolds to recruit RBPs to decay target mRNAs, and controlling protein degradation pathways (18-22). These studies indicate that lncRNAs are large and diverse transcripts that participate in modulating gene expression through various mechanisms.

\section{ROLE OF LncRNAs IN REGULATING GLUCOSE METABOLISM}

\section{Role of IncRNAs in Glucose Metabolism Under Physiological Conditions}

Role of IncRNAs in the Pancreas Under Physiological Conditions

The pancreas is involved in glucose metabolism. Pancreatic $\beta$-cells maintain blood glucose levels within a physiologically relevant range by precisely adapting insulin secretion to circulating levels of nutrients (23). IncRNAs play key roles in

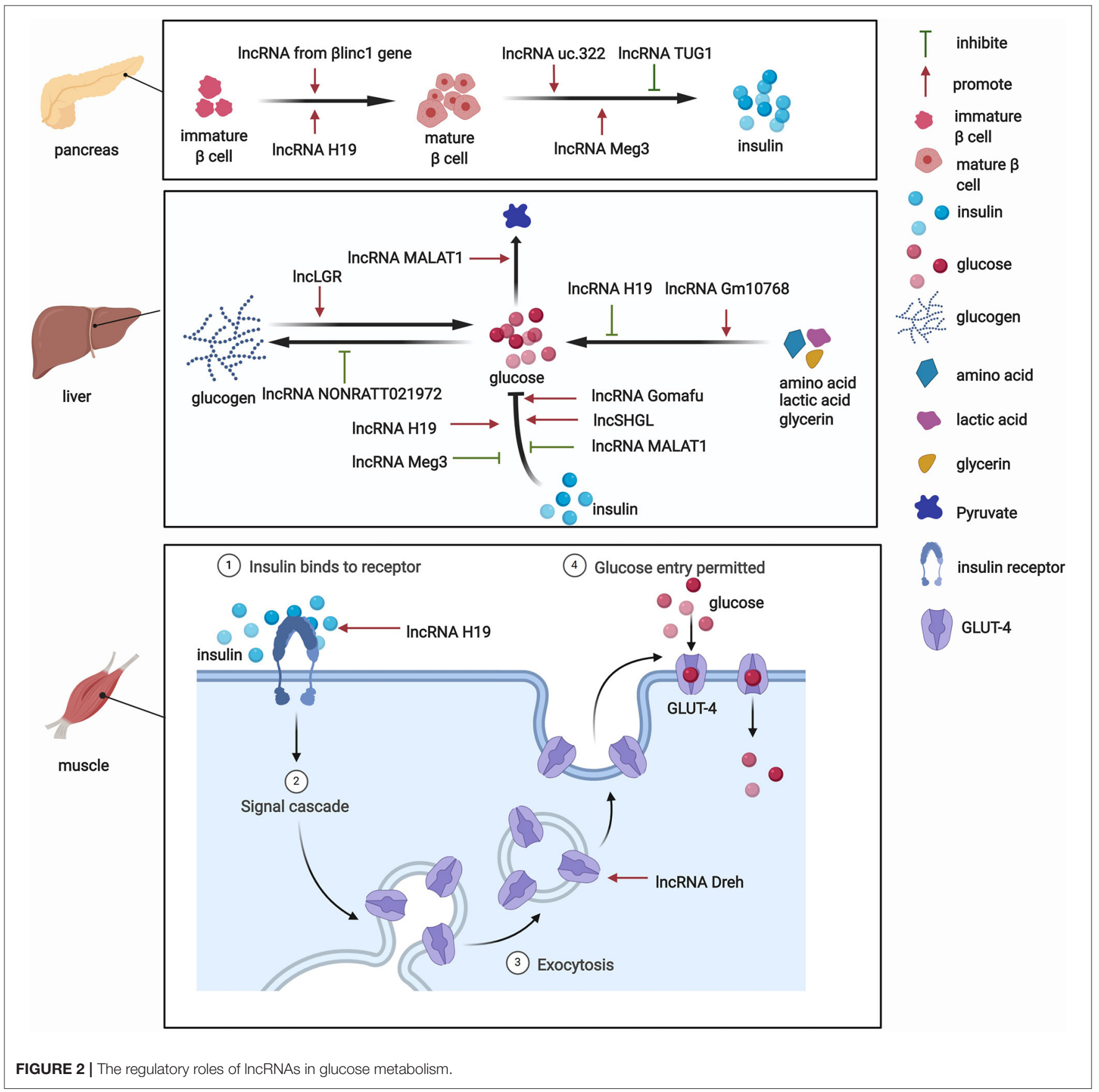


diverse processes that occur in pancreatic $\beta$-cells (Figure 2). The expression of lncRNAs in pancreatic islet cells is often highly tissue-specific, associated with clusters of open chromatins, and located in the genomic vicinity of transcription factors that are involved in $\beta$-cell development and related functions (24-26). The development of pancreatic $\beta$-cells occurs during the neonatal period. Pancreatic $\beta$-cells expand throughout the neonatal period. Defects in this process can predispose individuals to abnormal glucose metabolism or even diabetes during adulthood. Sanchez-Parra et al. found that lncRNA H19 regulated the expansion process of pancreatic $\beta$-cells through miRNA let-7 and the Akt signaling pathway (27). After silencing lncRNA H19, the $\beta$-cell expansion process decreased in newborns, whereas the re-expression of lncRNA H19 promoted the proliferation of $\beta$-cells in adults (27). The $\beta$ linc1 gene encodes a lncRNA that can influence islet $\beta$-cell formation and function (28). Luis et al. found that Blinc1 knockout mice were glucose-intolerant and had aberrant $\beta$ cells and endocrine development (28). At the molecular level, in the absence of Blinc1, many genes (e.g., Neurod1) that are involved in the specification of endocrine progenitors and maturation and function of $\beta$-cells were dysregulated (28). These studies suggest that lncRNAs participate in the regulatory process of $\beta$-cell development, but more studies need to explore the role of other lncRNAs in the development of pancreatic $\beta$-cells.

In addition to their impact on the growth of pancreatic $\beta$-cells, lncRNAs also regulate the biogenesis and secretion of insulin and thus indirectly mediate glucose metabolism. lncRNAs regulate the process of insulin biogenesis. For example, lncRNA Meg3 was shown to epigenetically regulate the expression of transcription factors, including Rad21, Smc3, and $\operatorname{Sin} 3 \alpha$, via EZH2-driven H3K27 methylation in pancreatic $\beta$-cells (29). By inhibiting the expression of Rad21, Smc3, and $\operatorname{Sin} 3 \alpha, \operatorname{lncRNA}$ Meg3 promoted the expression of MafA and promoted the synthesis of insulin both in vivo and in vitro (29). This study confirmed the role of lncRNAs in the function of islet cells by affecting insulin synthesis. IncRNAs also participate in insulin secretion. For example, Zhao et al. found that the upregulation of IncRNA ultraconserved 322 (uc.322) expression increased the expression of the insulin transcription factors pancreatic and duodenal homeobox 1 and Forkhead box O1 (FoxO1), thereby promoting insulin secretion (30). Interestingly, lncRNA Meg3 influences insulin secretion. The suppression of lncRNA Meg3 expression in vitro impaired insulin synthesis and secretion and increased the apoptosis rate of $\beta$ cells, and these effects were mediated by the lower expression of Pdx-1 and MafA (31). Additionally, another lncRNA, TUG1, was highly expressed in pancreatic tissue compared with other organ tissues, and its expression was dynamically regulated by glucose in Nit-1 cells (32). The knockdown of lncRNA TUG1 expression increased the apoptosis ratio and decreased insulin secretion in $\beta$-cells both in vitro and in vivo (32). These changes may explain the critical role of lncRNAs in pancreatic islet cells and their influence on glucose metabolism.

\section{Role of IncRNAs in the Liver Under Physiological Conditions}

Besides their impact on pancreatic tissue, lncRNAs also exert functions by regulating glucose metabolism in other tissues. Various functions of the liver, particularly glucose metabolism, are performed by hepatocytes. The liver is responsible for the synthesis of glycogen via glycogenesis, the release of glucose into the blood through glycogenolysis, the breakdown of glycogen into glucose, and gluconeogenesis. Under physiological conditions, lncRNAs have functions in glucose metabolism (Figure 2). One lncRNA, hepatic glucokinase (GCK) repressor (lncLGR), can be induced by fasting. The physiological overexpression of lncLGR to mimic fasting suppressed GCK expression and reduced hepatic glycogen content in mice (33). Mechanistically, lncLGR can specifically bind to heterogenous nuclear ribonucleoprotein $\mathrm{L}$, which was further confirmed to be a transcriptional repressor of GCK, thereby establishing a lncRNAmediated mechanism that regulates hepatic GCK expression and glycogen deposition (33). This study demonstrated the essential role of lncRNAs in the regulatory process of glucose metabolism.

\section{Role of IncRNAs in Other Tissues Under Physiological Conditions}

lncRNAs were also shown to have functions in adipocytes under physiological conditions. For example, the lncRNA steroid receptor RNA activator 1 (SRA1) was the first functional lncRNA that was identified to regulate of adipogenesis (34). This study showed that SRA1 overexpression promoted adipogenesis by modulating $\operatorname{PPAR} \gamma$, which regulates the pro-adipogenic transcription program, and by modulating P38/c-Jun N-terminal kinase (JNK) phosphorylation in vitro (34). The knockdown of endogenous SRA1 inhibited 3T3-L1 preadipocyte differentiation (34), and SRA1 knockout improved insulin sensitivity and glucose tolerance (35). In addition, Zhang et al. found that the downregulation of lncRNA slincRAD expression impaired the development of adipose tissue, leading to abnormal glucose and lipid metabolism and generating a slim phenotype in both male and female mice (36). These studies highlighted a physiologically important role for lncRNAs in the development of adipocytes, which is closely associated with systemic insulin resistance.

Skeletal muscles play a pivotal role in regulating systemic glucose homeostasis. Recently, some studies have demonstrated the effects of lncRNAs on glucose metabolism in skeletal muscles (Figure 2). For example, the knockdown of the lncRNA Dreh in myotubes reduced glucose concentrations in the culture medium, increased glucose transport, and increased glucose transporter 4 (GLUT4) protein levels in C2C12 skeletal cells (37). In addition, the lncRNA H19 was shown to enhance muscle insulin sensitivity at least partially by activating the adenosine monophosphate-activated protein kinase signaling pathway, which appeared to increase glucose uptake and mitochondrial biogenesis and increase muscle insulin sensitivity (38). 


\section{Role of IncRNAs in Glucose Metabolism Under Pathological Conditions \\ Role of IncRNAs in Glucose Metabolism in the Liver Under Pathological Conditions}

Under pathological conditions, several pathways, including gluconeogenesis, are dysregulated and become core factors in different kinds of diseases (39). The dysregulation of hepatic gluconeogenesis might be attributable to alterations of the expression of gluconeogenic genes that are mediated by a complex interplay between transcription factors and other regulators, such as lncRNAs (40-42). For example, lncRNA H19 inhibition in vivo induced hyperglycemia and impaired glucose, insulin, and pyruvate tolerance in liver tissue. These functions of lncRNA H19 might derive from an increase in hepatic transcript levels of gluconeogenic genes and the FoxO1 gene (42). Goyal et al. also reported important functions of lncRNA H19 (43). They found that H19 depletion in HepG2 cells impaired insulin signaling and increased the nuclear localization of FoxO1 (43). Moreover, based on genomewide methylation and transcriptome analyses, the role of H19 was highlighted in the liver. One study found that lncRNA H19 knockdown in hepatic cells altered the promoter methylation and expression of Hnf4a (a master gluconeogenic transcription factor), and this regulation was recapitulated in vivo (44).

In addition to lncRNA H19, some studies have explored the potential role of other lncRNAs in liver tissue. In high-fat diet-fed mice, lncRNA Meg3 was upregulated in hepatocytes (45). The knockdown of lncRNA Meg3 might mediate decreases in the expression of FoxO1 and the FoxO1 downstream targets phosphoenolpyruvate carboxykinase and the glucose-6-phosphatase catalytic subunit to improve impairments in glucose and insulin tolerance in liver tissue (46). Additionally, lncRNA Gomafu inhibited hepatic glucose production, improved insulin sensitivity, functioned as an miR-139 sponge, and led to the de-repression of its target gene FoxO1 in obese mice (47). The overexpression of hepatic IncRNA Gomafu resulted in an increase in random and fasting blood glucose levels in mice (47). The expression of a novel liver-enriched lncRNA, Gm10768, significantly increased in the liver in fasted mice and was induced by gluconeogenic hormonal stimuli (48). The knockdown of IncRNA Gm10768 improved glucose tolerance and hyperglycemia through miR-214-activating transcription factor 4 in liver tissue in diabetic $\mathrm{db} / \mathrm{db}$ mice (48). Song et al. reported that lncRNA NONRATT021972 levels in the liver increased in T2DM rats, and this increase was associated with an increase in blood glucose levels (49). At the molecular level, NONRATT021972 siRNA enhanced phospho-Akt levels, hepatic glucokinase expression, and hepatic glycogen synthesis (49). In human hepatic epithelial L-02 cells, lncRNA MALAT1 acts through HIF-1 $\alpha$ stabilization and may be a mediator that enhances arsenite-induced glycolysis (50). Based on these in vitro and in vivo studies, lncRNAs are critical in regulating glucose metabolism in liver tissue.

\section{Role of IncRNAs in Glucose Metabolism in Other Tissues Under Pathological Condition}

Several studies have investigated specific lncRNAs that might participate in regulating glucose metabolism in skeletal muscles under pathological condition. The recent study by Han et al. reported that a total of $144 \operatorname{lncRNAs}$, including 70 upregulated and 74 downregulated lncRNAs, were significantly differentially expressed in insulin-resistant skeletal muscle cells compared with control cells. The differentially expressed lncRNAs were significantly enriched in the peroxisome proliferator-activated receptor (PPAR) signaling pathway and insulin signaling pathway (51). Zhang et al. performed bioinformatics analyses and identified 331 lncRNAs, including 172 upregulated and 159 downregulated lncRNAs, that were differentially expressed in skeletal muscle cells in $\mathrm{db} / \mathrm{db}$ mice, suggesting a critical role for the PPAR signaling pathway (52). Thus, IncRNAs have been demonstrated to participate in glucose metabolism in skeletal muscles, but the mechanisms by which this occurs are not fully understood and require further exploration.

Only a few studies have explored the association between lncRNAs and adipocytes in glucose metabolism under pathological condition. For example, Yang et al. identified a lncRNA that regulates glucose homeostasis in human adipose tissue based on a microarray assay. They found that a decrease in $\ln \mathrm{RNA}$ uc001kfc. 1 could be a cis regulator of phosphatase and tensin homolog (PTEN) to enhance insulin sensitivity in white adipocytes in obese patients (53). However, more research is needed to explore the influence of lncRNAs in adipocytes from the perspective of glucose metabolism.

\section{ROLE OF LncRNAs IN REGULATING LIPID METABOLISM}

LncRNAs affect gene expression that is involved in lipid metabolism (Table 1). Accumulating studies have revealed that lncRNAs participate in lipid metabolism by influencing the expression of key genes, networks, and pathways that are involved in cholesterol and triglyceride biosynthesis, cholesterol transport, lipid uptake, and efflux (Figure 3).

\section{Role of IncRNAs in Cholesterol and Triglyceride Biosynthesis}

Cholesterol and triglyceride biosynthesis play an important role in regulating lipid metabolism. Several studies have shown that lncRNAs participate in expression of the transcription factor SREBP, which controls the expression of numerous enzymes that are required for endogenous cholesterol, fatty acid (FA), triacylglycerol, and phospholipid synthesis $(59,87,88)$. The SREBP family is divided into three isoforms (SREBP-1a, SREBP1c, and SREBP-2) that preferentially activate the transcription of cholesterol biosynthesis genes (88). Huang et al. showed that lncARSR overexpression increased the expression of 3-hydroxy3-methyl-glutaryl-coenzyme A reductase (HMGCR), the ratelimiting enzyme of cholesterol synthesis, and promoted hepatic cholesterol biosynthesis in vivo. Mechanistically, lncARSR 
TABLE 1 | The effect of IncRNAs in lipid metabolism.

\begin{tabular}{|c|c|c|c|c|c|c|}
\hline Name & Year & Cell type/Model & IncRNA & Target & Functions in lipid metabolism & References \\
\hline Huang et al. & 2018 & C57BL6/J mice & IncARSR & $\begin{array}{l}\text { SREBP-2, } \\
\text { HMGCR }\end{array}$ & $\begin{array}{l}\text { Promote cholesterol biosynthesis via } \\
\text { PI3K/Akt/SREBP-2/HMGCR pathway }\end{array}$ & $(54)$ \\
\hline Sallam et al. & 2016 & $\begin{array}{l}\text { Mouse primary hepatocytes } \\
\text { and peritoneal macrophages }\end{array}$ & IncRNA LeXis & $\begin{array}{l}\text { SREBP-2, } \\
\text { HMGCR }\end{array}$ & $\begin{array}{l}\text { Reduce cholesterol biosynthesis through } \\
\text { reducing the expression of SREBF2 and } \\
\text { HMGCR via preventing the Raly-mediated } \\
\text { recruitment of RNA polymerase II }\end{array}$ & (55) \\
\hline Liu et al. & 2015 & HepG2 cells & AT102202 & HMGCR & $\begin{array}{l}\text { Reduce cholesterol biosynthesis through } \\
\text { downregulating HMGCR }\end{array}$ & $(56)$ \\
\hline Liu et al. & 2018 & $\begin{array}{l}\text { Hepa1cell, mouse primary } \\
\text { hepatocytes and mouse liver }\end{array}$ & $\mathrm{H} 19$ & SREBP-1C & $\begin{array}{l}\text { Promote triacylglycerol biosynthesis through } \\
\text { PTBP1/SREBP-1c pathway }\end{array}$ & $(57)$ \\
\hline Zhao et al. & 2018 & $\begin{array}{l}\text { Mouse primary hepatocytes } \\
\text { and CRISPR/Cas9 mice }\end{array}$ & Blnc1 & SREBP-1C & $\begin{array}{l}\text { Promote triacylglycerol biosynthesis via binding } \\
\text { to transcription factor EBF2 }\end{array}$ & (58) \\
\hline Yan et al. & 2016 & $\begin{array}{l}\text { Livers of ob/ob mice and } \\
\text { HepG } 2 \text { cells }\end{array}$ & MALAT1 & SREBP-1C & $\begin{array}{l}\text { Promote triacylglycerol biosynthesis via } \\
\text { increasing nuclear SREBP-1c protein }\end{array}$ & (59) \\
\hline Dong et al. & 2019 & $\begin{array}{l}\text { Mouse normal liver cell line and } \\
\text { Arsenic-fed mice }\end{array}$ & PU.1 AS & SREBP-1C & $\begin{array}{l}\text { Reduce triacylglycerol biosynthesis via through } \\
\text { EZH2/Sirt6/SREBP-1c pathway }\end{array}$ & $(60)$ \\
\hline Li et al. & 2017 & Huh7 cells and C57BL/6J mice & IncRAN HR1 & $\begin{array}{l}\text { SREBP }-1 \mathrm{c} \text { and } \\
\text { FAS }\end{array}$ & $\begin{array}{l}\text { Reduce triacylglycerol biosynthesis by } \\
\text { repressing SREBP-1c gene expression. }\end{array}$ & $(61)$ \\
\hline Lan et al. & 2019 & CBRH-7919 cells and E3 rat & IncHC & PPAR $\gamma$ & $\begin{array}{l}\text { Promote triacylglycerol biosynthesis by } \\
\text { miR-130b-3p/PPAR pathway }\end{array}$ & $(62)$ \\
\hline Hu et al. & 2014 & THP-1 cells and apoE $\mathrm{E}^{-/-}$mice & DYNLRB2-2 & $\mathrm{ABCA} 1$ & $\begin{array}{l}\text { Promote cholesterol efflux via } \\
\text { GPR119/GLP-1R/ABCA1 pathway }\end{array}$ & (63) \\
\hline Sallam et al. & 2018 & $\begin{array}{l}\text { Mouse primary peritoneal } \\
\text { macrophages and } \\
\text { hepatocytes, THP-1 cells and } \\
\text { Ldlr }^{-/-} \text {mice }\end{array}$ & MeXis & $\mathrm{ABCA} 1$ & $\begin{array}{l}\text { Promote cholesterol efflux through interacting } \\
\text { with and guiding promoter binding of DDX17 }\end{array}$ & $(64)$ \\
\hline Lan et al. & 2016 & CBRH-7919 cells and E3 rat & IncHC & ABCA1 & $\begin{array}{l}\text { Reduce cholesterol efflux through forming a } \\
\text { complex with hnRNPA2B1 to inhibit ABCA1 } \\
\text { and Cyp7a1 }\end{array}$ & (65) \\
\hline Meng et al. & 2019 & THP-1 cells and apoE $-/-$ mice & GAS5 & $\mathrm{ABCA} 1$ & $\begin{array}{l}\text { reduce cholesterol efflux via reducing } \\
\text { EZH2-mediated ABCA1 transcription inhibition }\end{array}$ & $(66)$ \\
\hline Hu et al. & 2015 & $\begin{array}{l}\text { Macrophage-derived foam } \\
\text { cells }\end{array}$ & RP5-833A20.1 & miR-382, NFIA & $\begin{array}{l}\text { Reduce cholesterol efflux via miR-382-5p/NFIA } \\
\text { pathway }\end{array}$ & $(67)$ \\
\hline Halley et al. & 2014 & $\begin{array}{l}\text { HepG2 cells and African green } \\
\text { monkeys }\end{array}$ & APOA1-AS & APOA1 & $\begin{array}{l}\text { Inhibit expression of APOA1 and formation of } \\
\text { HDL }\end{array}$ & (68) \\
\hline Qin & 2016 & ob/ob mice & APOA4-AS & APOA4 & Increase expression of APOA4 & (69) \\
\hline Ray & 2019 & $\begin{array}{l}\text { HepG2 cells and human } \\
\text { primary hepatocytes }\end{array}$ & BM450697 & LDLR & $\begin{array}{l}\text { Reduce lipid uptake by SREBP-1a/LDLR } \\
\text { pathway }\end{array}$ & $(70)$ \\
\hline Mitchel et al. & 2016 & Huh7 and HepG2 cells & RP1-13D10.2 & LDLR & Produce lipid uptake by elevating LDLR & $(71)$ \\
\hline Wang et al. & 2019 & THP-1 cells & NEAT1 & CD36 & $\begin{array}{l}\text { Increase lipid uptake in macrophages by } \\
\text { miR-342-3p/CD36 pathway }\end{array}$ & $(72)$ \\
\hline Li et al. & 2015 & C57BL/6 mice & IncLSTR & APOC2 & $\begin{array}{l}\text { Produce triglyceride clearance via } \\
\text { TDP-43/FXR/apoC2-dependent pathway }\end{array}$ & (73) \\
\hline Xu et al. & 2010 & 3T3-L1 cells & SRA1 & PPAR $\gamma$ & $\begin{array}{l}\text { Promote white preadipocyte differentiation } \\
\text { partly via binding to PPAR } \gamma\end{array}$ & (34) \\
\hline Liu et al. & 2018 & $\begin{array}{l}\text { Human adipose tissue-derived } \\
\text { mesenchymal stem cells }\end{array}$ & IncRNA TINCR & $\mathrm{C} / \mathrm{EBP}-\alpha$ & $\begin{array}{l}\text { Promote adipocyte differentiation via IncRNA } \\
\mathrm{TINCR} / \mathrm{miR}-31-5 \mathrm{p} / \mathrm{C} / \mathrm{EBP}-\alpha \text { feedback loop }\end{array}$ & $(74)$ \\
\hline Huang et al. & 2019 & 3T3-L1 cells & Meg3 & Dickkopf-3 & $\begin{array}{l}\text { Promote } 3 \text { T3-L1 cells preadipocyte } \\
\text { differentiation by acting as a miR-217 sponge }\end{array}$ & (75) \\
\hline Pang et al. & 2013 & 3T3-L1 cells & PU.1AS & PU.1 & $\begin{array}{l}\text { Promote adipogenesis through forming an RNA } \\
\text { duplex with PU.1 mRNA }\end{array}$ & (76) \\
\hline Shang et al. & 2018 & $\begin{array}{l}\text { Rat bone marrow } \\
\text { mesenchymal stem cells }\end{array}$ & $\begin{array}{l}\text { IncRNA } \\
\text { TCONS_00041960 }\end{array}$ & GILZ & $\begin{array}{l}\text { Inhibit adipogenesis acting as a miR-125a-3p } \\
\text { sponge }\end{array}$ & $(77)$ \\
\hline Liu et al. & 2018 & 3T3-L1 cells & GAS5 & PTEN & Inhibit adipogenesis as a miR-21a-5p sponge & $(78)$ \\
\hline Cai et al. & 2018 & $\begin{array}{l}\text { Mouse primary preadipocytes } \\
\text { and C57BL/6 J mice }\end{array}$ & AdipoQ AS & AdipoQ & $\begin{array}{l}\text { Inhibit adipogenesis through forming an RNA } \\
\text { duplex with AdipoQ mRNA }\end{array}$ & (79) \\
\hline
\end{tabular}


TABLE 1 | Continued

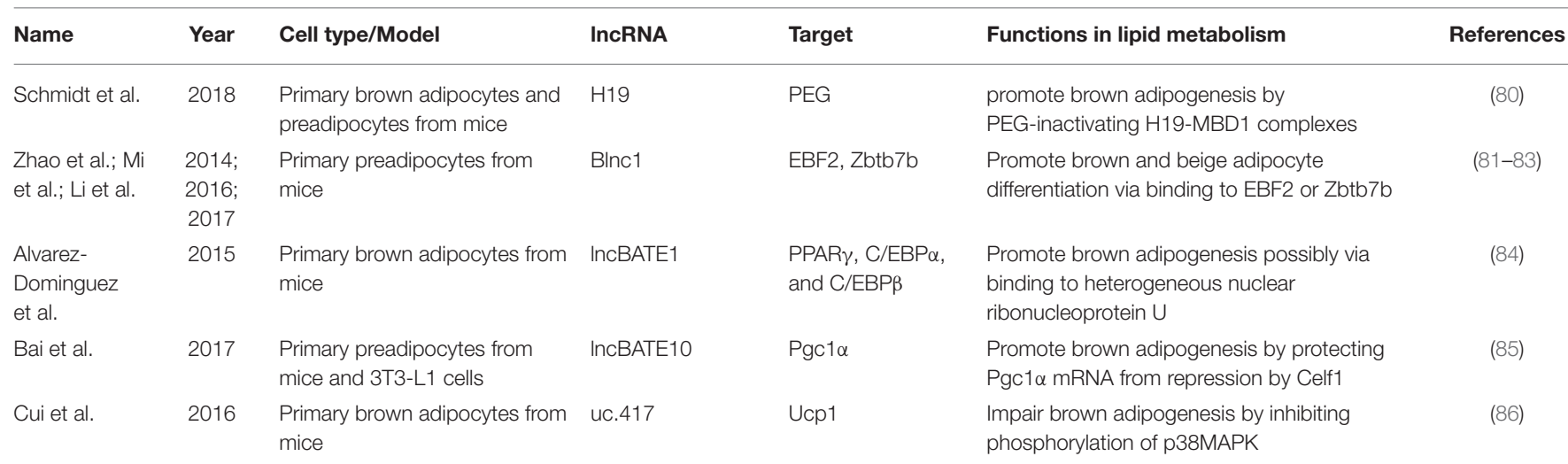

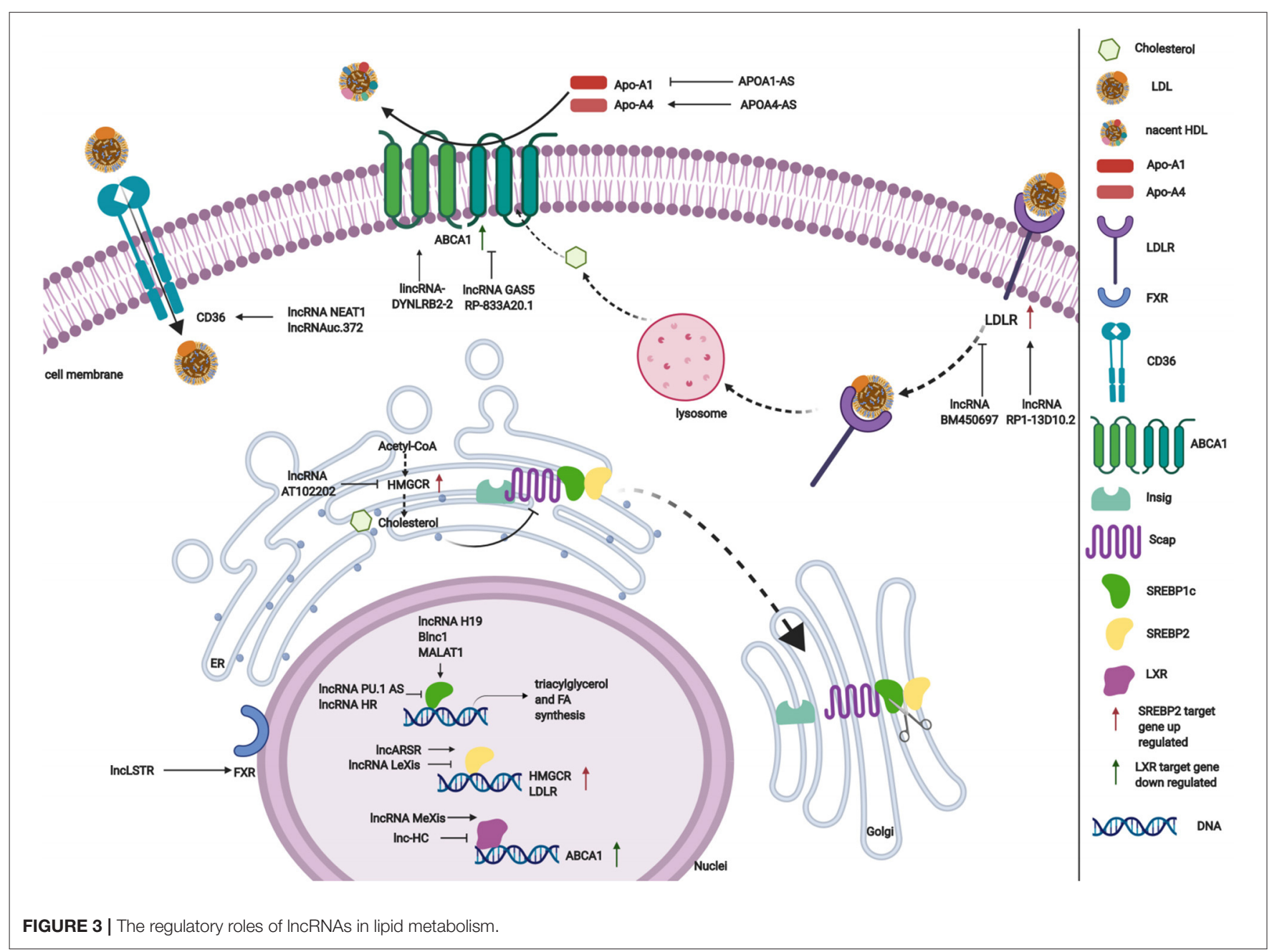

activates the phosphatidyl inositol 3-kinase (PI3K)/Akt pathway, thereby increasing the expression of mature SREBP-2, which is a primary transcription factor of HMGCR (54). In contrast to lncARSR, several other lncRNAs play negative regulatory roles in cholesterol biosynthesis. For example, lncRNA LeXis expression increased in the liver when mice were fed a Western diet and when liver $\mathrm{X}$ receptors (LXRs) were pharmacologically activated, thus demonstrating that lncRNA LeXis functioned as a modulator of genes that are involved in cholesterol homeostasis. Activated LeXis in chow-fed mice reduced the expression of cholesterol biosynthesis genes, including SREBF2 and HMGCR, and decreased serum and hepatic cholesterol levels. LeXis was 
TABLE 2 | The effect of IncRNAs on glucose metabolism in cancers.

\begin{tabular}{|c|c|c|c|c|c|}
\hline Name & Year & Cancer & IncRNA & Effect on glucose metabolism & References \\
\hline Zheng et al. & 2019 & $\begin{array}{l}\text { Hepatocellular } \\
\text { carcinoma }\end{array}$ & LINC01554 & $\begin{array}{l}\text { Inhibit Warburg effect via degradation of PKM2 and } \\
\text { inhibiting the Akt/mTOR signaling pathway }\end{array}$ & $(109)$ \\
\hline Malakar et al. & 2019 & $\begin{array}{l}\text { Hepatocellular } \\
\text { carcinoma }\end{array}$ & IncRNA MALAT1 & $\begin{array}{l}\text { Promote glycolysis and inhibit gluconeogenesis by } \\
\text { Enhancing mTOR-Mediated Translation of TCF7L2 }\end{array}$ & $(110)$ \\
\hline Tang et al. & 2019 & Colorectal cancer & IncRNA GLCC1 & $\begin{array}{l}\text { Increase glycolytic metabolism by stabilizing c-Myc from } \\
\text { ubiquitination }\end{array}$ & $(111)$ \\
\hline Feng et al. & 2019 & Colorectal cancer & LINC00504 & $\begin{array}{l}\text { Increase lactate production, glucose uptake, and pentose } \\
\text { phosphate pathway }\end{array}$ & $(112)$ \\
\hline Li et al. & 2019 & Esophageal cancer & LINC00184 & $\begin{array}{l}\text { Promote glycolysis by enhancing the promoter methylation } \\
\text { of PTEN }\end{array}$ & $(113)$ \\
\hline Ma et al. & 2019 & $\begin{array}{l}\text { Pancreatic } \\
\text { adenocarcinoma }\end{array}$ & IncRNA HOTAIR & $\begin{array}{l}\text { Increase lactate production, glucose uptake and ATP } \\
\text { production by upregulating HK-2 }\end{array}$ & $(114)$ \\
\hline Chen et al. & 2019 & Osteosarcoma & IncRNA HAND2-AS1 & Inhibit glucose uptake & $(115)$ \\
\hline Chu et al. & 2019 & $\begin{array}{l}\text { Oral squamous cell } \\
\text { carcinoma }\end{array}$ & LncRNA ELF3-AS1 & Increase glucose metabolism by upregulating GLUT1 & $(116)$ \\
\hline Cheng et al. & 2019 & Glioblastoma & IncRNA-XIST & $\begin{array}{l}\text { Promote glucose metabolism by acting as a miR-126 } \\
\text { sponge }\end{array}$ & $(117)$ \\
\hline Li et al. & 2018 & $\begin{array}{l}\text { Hepatocellular } \\
\text { carcinoma }\end{array}$ & IncRNA Ftx & $\begin{array}{l}\text { Increase Warburg effect by influencing the PPAR signaling } \\
\text { pathway }\end{array}$ & $(118)$ \\
\hline Kang et al. & 2018 & Osteosarcoma & IncRNA HAND2-AS1 & Inhibit glucose uptake and lactate production & $(119)$ \\
\hline Han et al. & 2018 & Osteosarcoma & IncRNA TUG1 & $\begin{array}{l}\text { Increase glucose consumption and lactate production by } \\
\text { upregulating HK-2 }\end{array}$ & $(120)$ \\
\hline Sun et al. & 2018 & Acute myeloid leukemia & IncRNA ANRIL & $\begin{array}{l}\text { Increase glucose uptake by inhibiting } \\
\text { AdipoR1-AMPK/SIRT1 signaling pathway }\end{array}$ & $(121)$ \\
\hline Zhang et al. & 2018 & Acute myeloid leukemia & IncRNA UCA1 & $\begin{array}{l}\text { Promote glycolysis through the microRNA-125a/HK-2 } \\
\text { pathway }\end{array}$ & $(122)$ \\
\hline Yang et al. & 2018 & Multiple myeloma & IncRNA PDIA3P & $\begin{array}{l}\text { Increase G6PD expression and pentose phosphate } \\
\text { pathway }\end{array}$ & $(123)$ \\
\hline Wang et al. & 2018 & $\begin{array}{l}\text { Oral squamous cell } \\
\text { carcinoma }\end{array}$ & Inc-p23154 & $\begin{array}{l}\text { Promote glycolysis by facilitating GLUT1 expression and } \\
\text { inhibiting miR-378a-3p transcription }\end{array}$ & $(124)$ \\
\hline Xing et al. & 2018 & Breast cancer & LINC00538 (YIYA) & $\begin{array}{l}\text { Promote glycolysis by regulating CDK6-dependent } \\
\text { phosphorylation of the fructose bisphosphatase PFK2 }\end{array}$ & $(91)$ \\
\hline Luan et al. & 2018 & Malignant melanoma & IncRNA H19 & $\begin{array}{l}\text { Promote glucose metabolism by acting as a miR-106a-5p } \\
\text { sponge }\end{array}$ & $(125)$ \\
\hline Wei et al. & 2017 & $\begin{array}{l}\text { Hepatocellular } \\
\text { carcinoma }\end{array}$ & IncRNA HOTAIR & Promote glycolysis via mTOR/GLU1 pathway & $(126)$ \\
\hline Song et al. & 2017 & Osteosarcoma & IncRNA Pvt1 & $\begin{array}{l}\text { Increase glucose uptake and lactate production by } \\
\text { regulating miR- } 497 / \mathrm{HK} 2 \text { axis }\end{array}$ & $(127)$ \\
\hline Hu et al. & 2017 & Bladder cancer & IncRNA CASC8 & Inhibit glycolysis by interacting with FGFR1 & $(128)$ \\
\hline Rupaimoole et al. & 2016 & Ovarian cancer & IncRNA NRCP & $\begin{array}{l}\text { Promote glycolysis by activating STAT1 transcriptional } \\
\text { gene network }\end{array}$ & $(129)$ \\
\hline Li et al. & 2014 & Bladder cancer & IncRNA UCA1 & $\begin{array}{l}\text { Promote glycolysis through the } \\
\text { mTOR-STAT3/microRNA143 pathway }\end{array}$ & $(130)$ \\
\hline
\end{tabular}

also shown to interact with the heterogeneous ribonucleoprotein RALY and prevented the Raly-mediated recruitment of RNA polymerase II to promoters of cholesterol biosynthesis genes (55). Microarray analysis showed that another lncRNA, AT102202, influenced HMGCR in HepG2 cells, and AT102202 knockdown resulted in an increase in HMGCR expression in HepG2 cells (56).

Unlike SREBP-2, lncRNA-mediated SREBP-1c preferentially enhances the transcription of triacylglycerol and FA synthesis genes (88). Liu et al. showed that H19 expression was upregulated by FAs in hepatocytes and in diet-induced fatty liver, which further augmented triacylglycerol accumulation (57). At the molecular level, they found that H19 could interact with polypyrimidine tract-binding protein 1 (PTBP1) to facilitate its association with sterol regulatory element-binding protein $1 \mathrm{c}$ mRNA and protein, leading to increased stability and nuclear transcriptional activity (57). Wang et al. studied lncRNA H19mediated SREBP and found that H19 expression increased in oleic acid-induced steatosis and during the development of HFDinduced NAFLD. H19 activation induced lipid accumulation by upregulating both the MLXIPL transcriptional network and the mTORC1 signaling axis (including active SREBP) 
in vivo and in vitro (89). Brown fat $\operatorname{lncRNA} 1$ (Blnc1) has been shown to regulate adipocyte differentiation (81). It may also serve as a regulator of triacylglycerol biosynthesis. Zhao et al. showed that the overexpression of Blnc1 in primary hepatocytes significantly augmented the induction of SREBP1c, increased the expression of triacylglycerol biosynthesis genes, and induced hepatic steatosis and insulin resistance through LXR activation. At the molecular level, proteomic analysis of the Blnc1 ribonucleoprotein complex identified EDF1 as a component of the LXR transcriptional complex that acted in concert with Blnc1 to activate the lipogenic gene program (58). Yan et al. found that the palmitate-mediated augmentation of MALAT1 expression occurred concomitantly with an increase in SREBP1c expression in hepatic cells. MALAT1 knockdown decreased the palmitate-induced lipid accumulation and expression of nuclear SREBP-1c protein in HepG2 cells and primary mouse hepatocytes by reducing the binding of MALAT1 to SREBP-1c in the nucleus, thereby inhibiting its ubiquitination to stabilize SREBP-1c protein (59). Several lncRNAs are also involved in the transcriptional suppression of SREBP-1c expression $(60,61)$. For example, lncRNA PU.1 AS expression was significantly upregulated in the liver in chronic arsenic-feed mice, which exhibited a decrease in serum triglyceride levels (60). At the molecular level, PU.1 AS was shown to modulate triacylglycerol homeostasis by interacting with EZH2 protein to inhibit sirtuin 6 mRNA and protein expression, thereby decreasing the expression of SREBP-1c and lipid accumulation (60). Similar to PU.1 AS, lncRNA HR functions as a negative regulator of SREBP1c in the mouse liver (61). In vitro and in vivo, lncHR1 overexpression inhibited the activation of SREBP-1c and FAS and decreased triglyceride synthesis and lipid droplet formation in oleic acidinduced hepatic cells and high-fat diet-fed mice (61). In addition to the influence of lncRNAs on SREBP-1c, a reduction of lncHC expression increased triacylglycerol and FA biosynthesis by decreasing miR-130b-3p expression, thereby inducing PPAR $\gamma$ activation (62).

\section{Role of IncRNAs in Lipid Efflux}

Lipid efflux and reverse cholesterol transport are important steps in lipid homeostasis, playing important roles in removing and transporting excess lipids and cholesterol from intracellular stores. Abcal is a critical cholesterol efflux gene that encodes the plasma membrane transporter ATP-binding cassette transporter ABCA1, which transports excess cellular cholesterol from cells to its corresponding apolipoproteins (90). Several studies have explored the relationship between ABCA1 and lncRNAs (63, 66). Hu et al. found that oxidized LDL (ox-LDL) significantly induced lincRNA DYNLRB2-2 expression, which promoted ABCA1-mediated cholesterol efflux and inhibited inflammation through G protein-coupled receptor 119 in THP-1 macrophagederived foam cells (63). Similar to lincRNA DYNLRB2-2, lncRNA MeXis was shown to be upregulated in ox-LDL and LXR (GW3965) agonist-treated macrophages, which correlated with cellular lipid content. MeXis knockout mice exhibited a reduction of Abcal expression, and a loss-of-function of MeXis in mouse bone marrow cells altered chromosome architecture at the Abcal locus, impaired macrophage cholesterol efflux, and accelerated the development of atherosclerosis. MeXis was also shown to interact with and guide promoter binding of the transcriptional coactivator DDX17, followed by amplification of the LXR-dependent transcription of Abcal in macrophages (64). In contrast to the positive regulation of LXRs by MeXis, lncHC has antagonistic effects on LXR activity, demonstrating its function as a negative regulator of cholesterol metabolism both in vitro and in vivo (65). Mechanistic studies indicated that $\operatorname{lncHC}$ increased the expression of hnRNPA2B1 in the nucleus and formed an RNA-protein complex, which further bound to cholesterol $7 \alpha$-hydroxylase (Cyp7a1) and Abcal mRNAs and reduced their expression (91). Another lncRNA that has a negative effect on ABCA1 is growth arrest-specific 5 (GAS5) (66). A recent study showed that lncRNA GAS5 was mainly localized in the nucleus and highly expressed in THP-1 macrophage-derived foam cells in coronary heart disease. The knockdown of GAS5 increased cholesterol efflux and inhibited intracellular lipid accumulation in THP-1 macrophage-derived foam cells and homozygous apolipoprotein E (ApoE) knockout mice by reducing the EZH2-mediated transcriptional inhibition of ABCA1 by histone methylation (66). The overexpression of RP-833A20.1 in THP-1 macrophages may also decrease cholesterol efflux. RP5-833A20.1 appeared to exert its effects on cholesterol content in macrophages by increasing miR-382 levels to downregulate nuclear factor IA (NFIA) (67).

Lipoprotein formation is also important in regulating lipid metabolism by binding and transporting lipids to various tissues in the body for metabolism. Two AS lncRNAs, APOA1-AS and APOA4-AS, have been reported to regulate the expression of apolipoproteins that contribute to the formation or function of plasma lipoproteins $(68,69)$. Halley et al. identified APOA1-AS as a negative transcriptional regulator of APOA1, which is the major protein component of high-density lipoprotein (HDL) in plasma and plays a key role in reverse cholesterol transport both in vitro and in vivo. The inhibition APOA1-AS promoted ApoA1 gene expression, likely through the recruitment of suppressor of zeste 12 homolog and the histone-modifying enzyme lysinespecific demethylase 1 to the ApoA1 promoter (68). In contrast to APOA1-AS, APOA4-AS was found to be a concordant regulator of APOA4 expression, which is a major component of HDL and triglyceride-rich lipoprotein particles and controls liver triglyceride secretion (69). The expression of APOA4-AS and APOA4 was abnormally upregulated in ob/ob mice and patients with hepatic steatohepatitis. Mechanistic experiments showed that APOA4-AS knockdown reduced APOA4 expression, leading to a decrease in serum triglyceride content and total cholesterol in ob/ob mice by directly interacting with $\mathrm{HuR}$ and stabilizing APOA4 mRNA (69).

\section{Role of IncRNAs in Lipid Uptake and Excretion}

Low-density lipoprotein receptors (LDLRs) play a vital role in ingesting and removing LDL particles from the blood. Ray et al. reported that lncRNA BM450697 acted as a regulator of LDLRs. The silencing of lncRNA BM450697 resulted in the activation of LDLRs (70). At the molecular level, lncRNA BM450697 
decreased LDLR mRNA levels, which was likely attributable to the blockade of interactions with RNA polymerase II and possibly SREBP1a at the LDLR promoter (70). Unlike BM450697, lncRNA RP1-13D10.2 was shown to activate the transcription of LDLRs, but the mechanisms are unclear and require further exploration (71).

When lipids accumulate in the blood, LDL undergoes oxidation modifications so that it can be ingested by CD36 and scavenger receptors. Wang et al. found that NEAT1 expression significantly increased in THP-1 cells that were treated with ox-LDL, and miR-342-3p expression significantly decreased. The silencing of NEAT1 in THP-1 cells inhibited CD36 mRNA expression and decreased Oil-Red staining levels, total cholesterol, and triglyceride content through the modulation of miR-342-3p (72). Another lncRNA that affects CD36 is uc.372 (92). uc.372 expression of genes that are involved in lipid uptake and synthesis, including CD36, ACC, FAS, and SCD1 (93).

Excess lipid excretion depends on bile acid metabolism, which is mediated by nuclear farnesoid $\mathrm{X}$ receptors that regulate genes that are involved in bile acid synthesis, including sterol 12 $\alpha$-hydroxylase (Cyp8b1) and Cyp7a1 (94). Li et al. found that a lncRNA, liver-specific triglyceride regulator (lncLSTR), in mice had an essential physiological function in mammalian lipid homeostasis via the bile acid pathway. They found that the liver-specific knockdown of lncLSTR in mice markedly reduced plasma triglyceride levels. They also found that lncLSTR knockdown decreased the binding with TDP-43, inhibited Cyp8b1 gene expression, and increased the ratio of muricholic acid to cholic acid in bile acid. Changes in bile acid composition activated FXRs to increase apolipoprotein C2 levels, resulting in greater triglyceride clearance in mice (73).

\section{Role of IncRNAs in Regulating Lipid Metabolism in Adipogenesis}

Adipogenesis is the process by which preadipocytes develop into mature white, brown, or beige adipocytes, contributing to both lipid storage and clearance, which are associated with lipid metabolism. Emerging evidence indicates the importance of lncRNAs in adipogenesis (Table 1). For example, Qi et al. found significant alterations of the expression of 114 lncRNAs in adipogenic cells during the adipogenic trans-differentiation of myoblasts (95). They also found that the lncRNA GM43652 had the highest expression levels in adipogenic cells. Knockdown of GM43652 negatively influenced lipid deposition in transdifferentiated myoblasts (95). Additionally, the transcriptomic analysis of primary preadipocytes, brown and white adipocytes, and cultured adipocytes during adipogenesis showed that the expression of 175 lncRNAs was significantly altered during the differentiation of adipocytes (96). These findings indicate that lncRNAs play vital roles in adipogenesis.

\section{Role of IncRNAs in White Adipocyte Adipogenesis}

White adipocytes are derived from white adipose tissue and control the storage of triacylglycerol. As mentioned above, many lncRNAs have been shown to be related to adipogenesis and might be bound at their promoters by key transcription factors, such as PPAR $\gamma$ and CCAAT/enhancer-binding protein
$\alpha(\mathrm{C} / \mathrm{EBP} \alpha)(96)$. For example, the lncRNA SRA1 has been demonstrated to promote preadipocyte differentiation partly via binding to PPAR $\gamma$ (34). Liu et al. found that terminal differentiation-induced ncRNA (TINCR) modulated adipogenic differentiation in human adipose tissue-derived mesenchymal stem cells by serving as a ceRNA for miR-31 to target C/EBP- $\alpha$ (74). Similar to lncRNA TINCR, Huang et al. found that lncRNA Meg3 might induce the differentiation of 3T3-L1 preadipocytes by acting as a miR-217 sponge (75). Furthermore, antisense lncRNAs, such as PU.1AS, have been shown to be involved in adipogenesis (76). PU.1AS might regulate adipogenesis by forming an RNA duplex with PU.1 mRNA and inhibiting PU.1 mRNA translation (76). In addition to the above lncRNAs, the potential role of other lncRNAs in adipogenesis, including GM43652, GM15290, ADINR, Paral1, and NEAT1 have also been shown to be positively related to adipogenesis $(95,97-100)$.

In contrast to the functions of lncRNAs that are described above, the lncRNAs TCONS_00041960 and lncRNA GAS5 act as sponges of microRNAs to negatively mediate adipogenesis (77, 78). At the molecular level, Shang et al. found that TCONS_00041960 inhibited the adipogenesis of rat bone marrow mesenchymal stem cells by acting as a competing endogenous RNA that interacted with miR-125a-3p to regulate GILZ, which inhibits the adipogenic regulator PPAR $\gamma$ and blocks adipocyte differentiation (77). GAS5 plays a suppressive role in the adipogenesis of $3 \mathrm{~T} 3-\mathrm{L} 1$ cells through an miRNAbased regulatory mechanism and might indirectly improve the expression of PTEN by repressing miR-21a-5p (78). An antisense lncRNA, adiponectin AS, was shown to inhibit adipogenesis by transferring from the nucleus to the cytoplasm and forming an AdipoQ AS lncRNA/AdipoQ mRNA duplex to suppress adiponectin mRNA translation in mouse primary preadipocytes and adipose tissues from high-fat-diet-fed mice (79). Other lncRNAs, such as U90926, MIR221HG, and RP11-20G13.3, have also been shown to be negatively related to adipogenesis (101-103). These studies indicate that lncRNAs regulate white adipogenesis through lncRNA-protein, lncRNA-mRNA, and lncRNA-miRNA interactions.

\section{Role of IncRNAs in Brown and Beige Adipocyte Differentiation}

Brown adipose tissue (BAT) and beige fat are responsible for thermogenesis. They are governed by a network of transcription factors and cofactors, including PR domain-containing 16 (PRDM16), PPAR $\gamma$, PPAR $\gamma$ coactivator $1 \alpha$ (PGC- $1 \alpha)$, early B-cell factor 2 (EBF2), and C/EBP $\beta(104,105)$. Accumulating studies have shown that several $\operatorname{lncRNAs}$ regulate thermogenic adipocyte biology by interfacing with these transcriptional regulators.

The function of maternally expressed, imprinted lncRNA H19 in brown adipocyte differentiation was studied by Schmidt et al. (80). Their results indicated that H19 overexpression promoted adipogenesis, oxidative metabolism, and mitochondrial respiration in brown but not white adipocytes. Mechanistically, H19 recruits paternally expressed gene (PEG)-inactivating H19-MBD1 complexes and acts as a BAT-selective PEG gatekeeper (80). Additionally, other transcripts, including Blnc1, dPrdm16, BATE1, and BATE10, have relevant 
functions in brown and beige adipocyte differentiation (8185 , 106). Chromatin immunoprecipitation with massively parallel DNA sequencing (ChIP-seq) in adipose tissues and during brown adipocyte differentiation showed that the expression of Blncl and transcriptional regulators of brown fat development (e.g., EBF2, Ucp1, and PPAR $\gamma$ ) was high during brown adipocyte differentiation (81). Further experiments elucidated the molecular mechanisms by which Blncl formed a ribonucleoprotein complex with heterogeneous nuclear ribonucleoprotein $U$ (hnRNPU) and EBF2 or zinc finger and BTB domain-containing $7 \mathrm{~b}$ to promote the thermogenic gene program and brown and beige adipocyte differentiation (8183). A study of de novo reconstruction of the human adipose transcriptome showed that 909 lncRNAs were specifically detected in BAT, and 169 conserved human lncRNAs regulated their nearby mRNAs (106). Notably, a functional lncRNA, lncdPrdm16, was shown to regulate adipogenesis in vitro and in vivo (106). To systematically study BAT-specific lncRNAs that are associated with adipogenesis in brown fat, AlvarezDominguez et al. reconstructed de novo transcriptomes of mouse brown fat, inguinal white fat, and epididymal white fat using RNA-seq and identified 127 BAT-restricted loci that were induced during differentiation (84). Among these lncRNAs, lncBATE1 was enriched in BAT compared with other organs. The silencing of lncBATE1 significantly reduced BAT-selective gene expression in primary brown adipocytes, which was partially rescued by exogenous lncBATE1 with mutated siRNA-targeting sites through an interaction with hnRNPU (84). IncBATE10, another BAT-enriched lncRNA, was required for full brown fat differentiation and white fat browning program by decoying Celf1 from PGC-1 $\alpha$, thereby protecting PGC- $1 \alpha$ mRNA from repression by Celf1 (85).

Contrary to the functions of lncRNAs that are described above, several lncRNAs may act as negative regulators of brown and beige adipocyte differentiation $(86,107)$. For example, Cui et al. showed that the ectopic expression of uc.417 impaired adipogenesis and the thermogenic program in brown adipocytes by moderately inhibiting the phosphorylation of p38 mitogenactivated protein kinase, which is essential for BAT activation (86). These data suggest that lncRNAs control brown and beige adipocyte differentiation through lncRNA-protein interactions.

\section{ROLE AND CLINICAL SIGNIFICANCE OF LncRNAs FOR GLUCOSE AND LIPID METABOLISM-RELATED DISEASE \\ Effect and Mechanism of Action of IncRNAs in Cancer}

Cancer is a major public health problem worldwide. A recent study estimated the number of new invasive cancer cases in the United States in 2020, with approximately $1,806,590$ diagnoses, equating to approximately 4,950 new cases each day (108). However, the mechanisms of cancer development are still unclear. Glucose metabolism consists of many steps and allows cells to access energy and transiently store it in adenosine triphosphate (ATP), which is necessary for the development of cancer. Some studies have suggested that lncRNAs may participate in the regulation of various cancers through effect on glucose metabolism (Table 2).

\section{Tumors of the Digestive System}

lncRNAs may participate in regulating glucose metabolism in different cancers of the digestive cancers. Hepatocellular carcinoma (HCC) is a leading cause of cancer-related morbidity and mortality, with the fifth highest cancer incidence in men and the ninth in women $(131,132)$. Several studies have explored the potential role of lncRNAs in regulating glucose metabolism in clinical HCC patients. For example, Zheng et al. tested 167 primary HCC samples and found that LINC01554 was frequently downregulated in patients with HCC (109). At the molecular level, LINC01554 may promote the ubiquitinmediated degradation of PKM2 and inhibit the Akt/mTOR signaling pathway to abolish the Warburg effect in vitro (109). Another study on 73 HCC patients and found that the lncRNA Ftx was upregulated in HCC samples and may promote the Warburg effect by influencing the PPAR signaling pathway (118). Wei et al. reported a marked increase in lncRNA HOTAIR expression in 84 HCC tissues (126). This lncRNA was shown to promote glycolysis by upregulating GLUT1 and activating mTOR signaling in HCC cells, whereas its knockdown suppressed this effect (126). In addition, the lncRNA MALAT1 was found to influence the development of HCC by regulating glucose metabolism, enhancing glycolysis, and inhibiting gluconeogenesis through elevating translation of the transcription factor TCF7L2 (110). Enhancement of translation of the lncRNA MALAT1 by TCF7L2 was also shown to be mediated by the upregulation of serine/arginine-rich splicing factor 1 (SRSF1) and activation of the mTOR complex 1 (mTORC1)-eukaryotic translation initiation factor 4E-binding protein 1 (4EBP1) axis (110). These studies demonstrate that lncRNAs regulate glucose metabolism in HCC and are potential therapeutic targets for the disease.

Colorectal cancer (CRC) kills nearly 700,000 people annually and has become the world's fourth deadliest cancer (133). Several studies have suggested a potential role for lncRNAs in glucose metabolism in CRC. Tang et al. evaluated 95 patients with CRC and found that the lncRNA GLCC1 was significantly upregulated compared with that in healthy controls. This lncRNA may stabilize the transcription factor c-Myc from ubiquitination by direct interaction with the HSP90 chaperon. The transcriptional modification pattern of c-Myc target genes, such as LDHA, consequently reprogrammed glycolytic metabolism toward CRC cell proliferation (111). In addition, LINC00504 was shown to be upregulated in CRC patients to promote colon cancer progression. This lncRNA might be a transcriptional regulator of $\mathrm{c}-\mathrm{Myc}$ that reprograms central metabolism, including glucose metabolism, the pentose phosphate pathway, and the tricarboxylic acid cycle (112). These studies strongly suggest the potential influence of lncRNAs on glucose metabolism in CRC, but further studies are needed to explore the detailed mechanisms.

In other cancers of the digestive system, such as esophageal cancer (EC) and pancreatic cancer, lncRNAs participate in the 
pathophysiological process by influencing glucose metabolism. One study on 84 patients with EC and found that LINC00184 was upregulated in EC tissues and may mediate glycolysis (113). At the molecular level, LINC00184 was shown to enhance the promoter methylation of PTEN by recruiting DNA (cytosine-5)-methyltransferase 1 (DNMT1), and the inhibition of PTEN promoter methylation suppressed EC cell glycolysis and improved mitochondrial oxidative phosphorylation (113). Additionally, one study revealed that the lncRNA HOTAIR was upregulated in pancreatic adenocarcinoma compared with the level in adjacent healthy tissues (114). Overexpression of the lncRNA HOTAIR increased tumor cell proliferation, lactate production, glucose uptake, and ATP production in pancreatic adenocarcinoma by upregulating hexokinase-2 (HK-2) (114). These findings provide new insights into the role of lncRNAs in cancers of the digestive system.

\section{Bone Tumors}

Osteosarcoma is a primary malignant bone tumor that most commonly affects children, adolescents, and young adults (134). However, the mechanism behind its development remains unclear and needs further investigation. Recent studies of osteosarcoma found that lncRNAs that potentially participate in glucose metabolism may influence tumor development in this condition. Chen et al. reported that the expression of the lncRNA HAND2-AS1 decreased in osteosarcoma tissues compared with that in healthy tissues (115). Knockdown of this lncRNA promoted osteosarcoma cell proliferation, increased glucose uptake, and upregulated GLUT1 expression (115). Interestingly, Kang et al. also explored the role of this lncRNA in osteosarcoma (119). They found that it was significantly upregulated in osteosarcoma cells compared with the level in normal cultured cells, and that its knockdown increased glucose uptake, lactate production, and the expression of a series of enzymes that are involved in energy metabolism, thus influencing the development of osteosarcoma (119). Based on these studies, HAND2-AS1 appears to be involved in osteosarcoma by influencing glucose metabolism, but its precise role and molecular mechanisms need further investigation.

The lncRNA TUG1 was shown to be overexpressed in osteosarcoma cells compared with the level in a normal osteoblastic cell line (120). Its knockdown inhibited glucose consumption, lactate production, and cell viability in osteosarcoma cells (120). At the molecular level, the aberrant expression of lncRNA TUG1 markedly affected the expression of HK-2 (120). Additionally, Song et al. reported that the expression of the lncRNA Pvt1 was increased specifically in osteosarcoma cells and tissues, and its upregulation of lncRNA Pvt1 was associated with a poor prognosis (127). Its overexpression increased glucose uptake, lactate production, and the expression of HK-2 in osteosarcoma cells, while its knockdown produced the opposite effects (127). These studies highlight the importance of lncRNAs in the development of osteosarcoma through the regulation of glucose metabolism, but the exact regulatory mechanisms that underlie the relationship between lncRNAs and osteosarcoma need further study.

\section{Genitourinary Malignancy}

Bladder cancer is the second most common genitourinary malignancy. There has been little progress in treatments for bladder cancer, and the mechanisms by which bladder cancer develops and progresses need further investigation. A recent study reported that the IncRNA CASC8 was significantly downregulated and associated with advanced-stage bladder cancer (128). Its overexpression was shown to significantly suppressed bladder cancer cell proliferation by reducing the glycolysis of bladder cancer cells and interacting with fibroblast growth factor receptor 1 (FGFR1) (128). Another lncRNA of the UCA1 gene, which was highly expressed in bladder carcinoma and enhanced the tumorigenic behavior of bladder cancer cells in vitro and in vivo $(135,136)$, promoted glycolysis through the mTOR-STAT3/microRNA143 pathway in bladder cancer cells, and UCA1-induced HK-2 was shown to be an important mediator in this process (130).

In addition to bladder cancer, IncRNAs also play roles in ovarian cancer, which is the most frequent cause of death among gynecologic malignancies. For example, the lncRNA NRCP (ceruloplasmin) was found to be highly upregulated in ovarian cancer. NRCP knockdown resulted in a significant increase in apoptosis, a decrease in cell proliferation, and a decrease in glycolysis compared with the levels in control cancer cells (129). NRCP is also an intermediate binding partner between STAT1 and RNA polymerase II and can lead to an increase in the expression of downstream target genes, such as glucose-6phosphate isomerase (129). These findings suggest the potential role of lncRNAs in glucose metabolism in ovarian cancer.

\section{Malignant Hemopathy}

Acute myeloid leukemia (AML) is the most common acute leukemia in adults, accounting for $\sim 80 \%$ of leukemia cases (137). Sun et al. found that the lncRNA ANRIL was upregulated in AML patients at diagnosis and downregulated in patients after complete remission. At the molecular level, the knockdown of ANRIL expression resulted in a decrease in glucose uptake and the inhibition of AML cell maintenance through the targeting of adiponectin receptors in vitro and in vivo (121). Knockdown of the lncRNA UCA1 was shown to play a beneficial role in overcoming chemoresistance in pediatric AML (122). A functional study showed that the knockdown of this lncRNA potentiated the cytotoxic effect of adriamycin (ADR) and inhibited HIF- $1 \alpha$-dependent glycolysis in ADR-resistant AML cells (122).

Multiple myeloma (MM) is the second most common hematologic malignancy. lncRNAs also regulate glucose metabolism in MM. For example, Yang et al. showed that the lncRNA PDIA3P was highly expressed in MM and associated with survival rate in MM patients (123). This lncRNA may also interact with c-Myc to enhance its transactivation and binding to the glucose 6-phosphate dehydrogenase (G6PD) promoter, stimulating G6PD expression and pentose phosphate pathway flux (123). This study elucidated crucial roles for lncRNAs in the regulation of glucose metabolism in MM, providing a potential therapeutic target for this disease. 


\section{Other Cancers}

Some studies have suggested that lncRNAs may be involved in glucose metabolism in other kinds of cancer. For example, a study of 112 patients with oral squamous cell carcinoma (OSCC) reported that the IncRNA ELF3-AS1 was upregulated and positively correlated with GLUT1. This lncRNA was shown to positively regulate OSCC cell proliferation through GLUT1 and reprogrammed glucose metabolism in vitro (116). In addition, a novel lncRNA, lnc-p23154, was upregulated in OSCC and affected glycolysis by facilitating GLUT1 expression and inhibiting miR-378a-3p transcription (124). These recent studies highlight the modulatory role of lncRNAs in glucose metabolism in OSCC.

In addition, in the case of breast cancer, the lncRNA LINC00538 (YIYA) was expressed in $\sim 40 \%$ of cases and correlated with cyclin-dependent kinase 6 (CDK6) expression and unfavorable survival outcomes (91). Its upregulation promoted glycolysis, was associated with cytosolic CDK6, and regulated the CDK6-dependent phosphorylation of fructose bisphosphatase PFK2, thus defining a functional role for this lncRNA in metabolic reprogramming in breast cancer (91).

In malignant melanoma, expression of the lncRNA H19 was shown to be increased in melanoma tissue and might function as a sponge of miR-106a-5p to upregulate E2F3 expression and consequently promote the glucose metabolism and growth of melanoma cells (125).

Finally, in glioblastoma, the lncRNA XIST was revealed to regulate glucose metabolism by targeting GLUT1 and GLUT3 through the miR-126-dependent insulin receptor substrate 1 (IRS1)/PI3K/Akt pathway and to positively control glioblastoma cell growth in vivo and in vitro (117).

\section{Clinical Significance of IncRNAs in Cancer}

Based on the above analysis, such lncRNAs involved in the regulation of cancers through glucose metabolism could be critical prognostic biomarkers or therapeutic targets. For example, Luan et al. reported that the level of the lncRNA H19 was increased in melanoma tissue and was correlated with poor prognosis of melanoma patients (125). In addition, LINP1 was found to promote the malignant phenotype of AML cells and to stimulate glucose metabolism, which was significantly upregulated in AML patients at diagnosis, but downregulated after complete remission (CR) (138). Moreover, UCA1 expression was found to be upregulated following ADRbased chemotherapy and its knockdown could overcome the chemoresistance of pediatric AML, indicating that it is to reasonably predictive of drug benefit (122). Moreover, in lung cancer, antisense oligonucleotides (ASO) blocking of MALAT1 was shown to prevent the development of metastasis in vivo $(139,140)$.

\section{Effect, Mechanism of Action, and Clinical Significance of IncRNAs in Metabolic Disease \\ Diabetes Mellitus}

Diabetes mellitus (DM) is a metabolic disorder that is characterized by abnormal glucose metabolism, including hyperglycemia, in fasting and postprandial states. Several lncRNAs have been shown to regulate glucose metabolism and be associated with the pathology of type $2 \mathrm{DM}$ (T2DM) $(38,53)$, involving changes in the growth of pancreatic $\beta$-cell, insulin synthesis, insulin secretion, and insulin signaling in target tissues (including liver, skeletal muscle, and adipocyte). For instance, Akerman et al. have demonstrated that the lncRNA PLUTO controlled $3 \mathrm{D}$ chromatin structure and the transcription of PDX1, a master regulator of pancreas development and $\beta$ cell differentiation, and that both PLUTO and PDX1 were downregulated in islets from organ donors with type 2 diabetes or impaired glucose tolerance, suggesting a potential role in DM (141). The lncRNA Meg3 has been demonstrated to affect the process of insulin biogenesis and be involved in the development of diabetes by inhibiting the expression of $\operatorname{Rad} 21, \operatorname{Smc} 3$, or $\operatorname{Sin} 3 \alpha$ via EZH2-driven H3K27 methylation (29). In another study, Fadista et al. reported that the lncRNA LOC283177 was coexpressed with master genes of islet function (MADD, PAX6, and SYT11). Meanwhile, its expression was positively associated with insulin exocytosis, but negatively with HbAlc levels. However, its function remained unknown (92). Dysregulation of insulin signaling was another common underlying mechanism of T2DM. Several lncRNAs have been emerged as regulators of insulin signaling $(43,44,142)$. As mentioned earlier, the hepatic lncRNA H19 has been identified as the most significantly downregulated lncRNA in the livers of $\mathrm{db} / \mathrm{db}$ mice (43). Inhibition of hepatic H19 impaired insulin signaling and increased the expression of gluconeogenic genes, possibly by regulating FoxO1 nuclear levels (43). In contrast to the results of that study, Zhang et al. showed that H19 expression was chronically increased in diet-induced diabetic mouse liver and that liver-specific H19 overexpression promoted hyperglycemia and insulin resistance. At the molecular level, they demonstrated that H19-induced alteration in promoter methylation and expression of Hnf4a may contribute to the underlying mechanism (44). Additionally, skeletal muscle $\mathrm{H} 19$ can also regulate insulin signaling. Gao et al. reported that $\mathrm{H} 19$ was significantly decreased in muscle of T2DM patients and insulin-resistant rodents. Mechanistically, H19 could act as a molecular sponge to inhibit let-7 miRNA, this reduction led to increased bioavailability of let-7, causing reduced expression of let-7 targets, eventually resulting in impaired insulin sensitivity and increased blood glucose level (142).

Diabetes mellitus and its complications are major health concerns that can be mitigated by implementing early preventive measures in people who are at high risk. However, current risk models perform suboptimally with regard to predicting individual diabetes risk (143). As mentioned above, several lncRNAs involved in the pathogenesis of T2DM may serve as diagnostic biomarkers or therapeutic targets for T2DM. Saeidi et al. studied 100 T2DM patients and 100 non-diabetic controls and reported that the IncRNAs LY86-AS1 and HCG27_201 were downregulated in peripheral blood mononuclear cells (PBMCs) in T2DM patients compared with levels in a control group. They also found that the expression of both of these lncRNAs was negatively correlated with fasting blood sugar levels (144). In addition, Sathishkumar et al. reported a significant increase in the expression of several lncRNAs (e.g., HOTAIR, Meg3, LET, MALAT1, MIAT, CDKN2BAS1/ANRIL, XIST, PANDA, 
GAS5, Linc-p21, ENST00000550337.1, PLUTO, and NBR2) and a significant decrease in the expression of lncRNAs THRIL and SALRNA1 in 30 patients with T2DM compared with the levels in 30 control subjects (145). A recent meta-analysis by Zhang et al. also revealed that abnormal lncRNA expression had diagnostic value in T2DM patients. As diagnostic biomarkers, lncRNAs showed relatively high diagnostic accuracy for T2DM and prediabetes, with sensitivity of 0.71 and 0.76 , respectively (146). Moreover, it has been asserted that the pathogenesis of gestational diabetes mellitus (GDM) is similar to that of T2DM (147). Several studies have shown that lncRNAs such as PVT1, MALAT1, and AC092159.2, could be novel biomarkers to predict and diagnose GDM, although the molecular mechanisms involved were unclear (148-150). These effects demonstrate the potentially vital roles of $\operatorname{lncRNAs}$ in DM and provide evidence that lncRNAs may serve as clinical risk and diagnostic biomarkers of T2DM. However, research on lncRNAs as possible therapeutic targets for T2DM has been scarce. High-yield extracellular vesiclemimetic nanovesicle contained lncRNA H19 was considered an effective treatment that accelerated the healing process in diabetes-associated chronic wounds (151).

\section{Obesity}

Obesity has reached epidemic proportions worldwide and is an important risk factor for T2DM, hypertension, cardiovascular disease, and certain cancers. However, effective treatments are limited. The lncRNA-mediated dysfunction of glucose and lipid metabolism, especially their effects on adipocytes, has been closely related to obesity. LncRNA HOXA1-AS1 expression levels were positively correlated with adipogenesis, and its expression was significantly higher in obese patients than in controls (152). Knockdown of the lncRNA HOXA11AS1 using siRNA attenuated adipocyte differentiation, leading to suppression the transcription of adipogenic genes, such as CEBP- $\alpha$, DGAT2, CIDEC, and perilipin (152). Another IncRNA, named AC092159.2, was shown to be positively associated with body mass index (BMI) and obesity. Its overexpression promoted adipocytes differentiation while its knockdown led to an adipogenic defect. Mechanistically, this lncRNA enhanced human adipocytes differentiation, possibly by regulating TMEM18 (153). Conversely, obese mice were shown to have low lnc-U90926 expression in subcutaneous and visceral adipose tissue. The overexpression of lnc-U90926 attenuated 3T3-L1 adipocyte differentiation via inhibiting the transactivation of PPAR $\gamma 2$ or PPAR $\gamma$ (101). Increasing BAT thermogenesis in mice and humans can improve obesity. In one study, it was observed that the lncRNA H19 was related to brown adipocyte differentiation and was decreased in obesity in BAT under an obese state. H19 overexpression promoted while knockdown of H19 impaired adipogenesis in brown adipocytes through recruiting PEG (80). In addition, H19 transgenic mice were shown to be protected from diet-induced obesity (80). Moreover, SREBP-1c has been shown to be a critical transcription factor in FA synthesis (88). SREBP-1c expression was increased in the liver of obese patients (154). Finally, MALAT1 may induce lipid accumulation and insulin resistance by increasing SREBP-1c and target gene expression (59).
Although the precise molecular network that regulates obesity remained unclear, such IncRNAs may be involved in obesity and could be novel therapeutic targets for this condition. The use of synthetic molecules or bioactive compounds that mimic or inhibit specific lncRNAs or modulate the expression of specific IncRNAs through the application of siRNA and antisense oligos, as well as applying the powerful CRISPRCas9 gene editing approach, may become new molecular treatment strategies.

\section{Atherosclerosis}

Atherosclerosis is a leading cause of mortality from cardiovascular disease. The dysfunction of lipid metabolism is well-known to be a significant risk factor for atherosclerosis. Lipid disorders cause lipoprotein accumulation within middle and large artery walls, thus triggering atherosclerosis (155). Several lncRNAs are involved in lipid metabolism-related disorders through the regulation of lipid synthesis, reverse cholesterol transport, and bile acid excretion $(63,66)$. The formation of macrophage foam cells, which play central roles in the initiation and progression of atherosclerotic plaques, has been shown to be closely related to DYNLRB2-2, MeXis, and RP5-833A20.1 (63, 64, 67). Mechanistically, lincRNADYNLRB2-2 expression promoted ABCA1-mediated cholesterol efflux and inhibited inflammation through GPR119 in THP-1 macrophage-derived foam cells (63). MeXis increased ABCA1 expression in macrophages through interacting with and guiding promoter binding of DDX17 (124). RP5-833A20.1 downregulated NFIA in human foam-cell macrophages by modulating miR-382 levels (67). In addition, Meng et al. found that GAS5 deletion inhibited the progression of atherosclerosis by reducing EZH2-mediated ABCA1 transcription in ApoE knockout mice (66).

The IncRNA MALAT1 in peripheral blood cells has been implicated in left ventricular dysfunction in patients with myocardial infarction (MI) (156) and might be associated with lipid accumulation and insulin resistance (59). Indeed, atherosclerotic burden was significantly reduced in Ldlr knockout animals by treatment with an AAV8 vector expressing LeXis (157). At the molecular level, IncRNA LeXis overexpression improved atherosclerosis through reducing the expression of SREBF2 and HMGCR via preventing the Raly-mediated recruitment of RNA polymerase II (55). These findings demonstrate the feasibility of using lncRNAs as predictors and diagnostic markers of atherosclerosis and in mimetic therapeutic strategies. However, further studies are needed to explore the detailed molecular mechanisms of lncRNAs so that target gene therapy may proceed to clinical trials.

\section{NAFLD}

NAFLD is a common metabolic disorder of the liver that has emerged as a major public health problem with a high prevalence rate (12.9-46.0\% in various countries) (158). An increasing number of studies have explored the pathogenesis of NAFLD $(159,160)$, but effective strategies for preventing and treating NAFLD are still lacking. The accumulation of triglycerides 
within hepatocytes is a hallmark of NAFLD. Emerging evidence shows that some lncRNAs regulate triglyceride metabolism in hepatocytes and in a mouse model of NAFLD by controlling triglyceride biosynthesis and CD36-dependent lipid uptake $(59,93,161-163)$. In the liver of obese mice and patients with NAFLD, the expression of mouse lncSHGL and its human homolog lncRNA B4GALT1-AS1 was found to be decreased (161). Hepatic lncSHGL restoration reduced triglyceride content and improved hyperglycemia, insulin resistance, and steatosis in obese diabetic mice by activating the PI3K/Akt pathway and repressing the mammalian/mTOR/SREBP-1c pathway independent of insulin and calcium (161). Similarly, the lncRNA MALAT1 promoted hepatic steatosis and insulin resistance by increasing nuclear SREBP-1c stability (59). uc.372 expression was also shown to increase in the liver in $\mathrm{db} / \mathrm{db}$ mice, high-fat-diet-fed mice, and NAFLD patients through regulating CD36-dependent lipid uptake (93). Another study has showed that mice with knockout of the lncRNA SRA had decreased hepatic triglyceride content. Further experiments elucidated that SRA could inhibit the expression of adipose triglyceride lipase (ATGL), which is a key lipolytic enzyme, by repressing the transcriptional activity of FoxO1 (162). Moreover, the lncRNA MEG3 was significantly decreased in liver tissues of NAFLD patients (164). Mechanistically, Huang et al. demonstrated that MEG3 could act as a ceRNA for miR-21 to regulate LRP6 expression during liver lipid deposition (156).

Sun et al. performed a genome-wide analysis and found the aberrant expression of lncRNAs in liver tissue in NAFLD patients. A total of 1735 lncRNAs were differentially expressed in NAFLD samples compared with control samples (164). Di Mauro et al. also performed a genome-wide analysis and found that lncRNA RP11-128N14.5 expression was upregulated in liver tissue and serum in severe NAFLD patients compared with mild NAFLD patients and controls (165). These findings clearly suggest that lncRNAs may serve as non-invasive diagnostic markers and novel therapeutic targets for NAFLD in the future.

\section{CONCLUSIONS AND FURTHER PROSPECTS}

lncRNAs have broad implications in glucose and lipid metabolism in physiological and pathological conditions. They mediate various biological processes in different tissues and diseases. The lncRNAs involving in regulating glucose metabolism mainly participated in the development of pancreatic islet cells, insulin biogenesis, insulin secretion, and manipulate insulin signaling in peripheral tissues (including liver, skeletal muscles, and adipocytes). In addition, lncRNAs act in complex processes to regulate lipid metabolism via cholesterol and triglyceride biosynthesis by regulating expression of the transcription factor SREBP, lipid efflux by regulating ABCA1 expression and lipoprotein formation, LDLR- and CD36-dependent lipid uptake, bile acid metabolism, and adipogenesis. In pathological conditions, abnormal lncRNAs could participate in the regulation of various cancers and contribute to metabolic diseases, including T2DM, obesity, cardiovascular disease, and NAFLD through influencing glucose and lipid metabolism.

The diversity of responses that are observed in different tissues and diseases demonstrates the complex functions of lncRNAs in the body. This review should help to provide a better understanding of lncRNAs in glucose and lipid metabolism, potentially allowing better predictions of disease states and contributing to novel therapeutic strategies that exploit relevant signaling pathways. The studies described here have provided strong evidence that lncRNAs play vital roles in glucose and lipid metabolism, but a number of important questions remain unanswered. First, the precise molecular mechanism in different pathological conditions is still unclear. In addition, the expression levels of many lncRNAs are quite low, which brings some uncertainty regarding the reliability and reproducibility of large-scale lncRNA investigations. There are still other limitations associated with using circulating or tissue lncRNAs as biomarkers, difficulty measuring lncRNAs, low accuracy, and expensive procedures. Moreover, the poor DNA sequence conservation of lncRNAs across species can be an issue for the extrapolation of research results obtained from animal models to humans. For the translation of lncRNA-based therapy into clinical applications, the establishment of a better delivery system should also be considered. Therefore, future work on the involvement of lncRNAs in glucose and lipid metabolism might include the following:

1) Effect of crosstalk of exosome-derived lncRNAs among the tissues.

2) A thorough functional characterization of lncRNAs in glucose and lipid metabolism-related disease, at both the molecular and the cellular levels.

3) Retrieving the most promising candidates for therapeutic targets from the huge amount of sequencing data available.

4) Identifying panels of lncRNAs for optimal accuracy for diagnosing glucose and lipid metabolism-related disease.

5) Exploring glucose and lipid metabolism-related disease risk reduction models using lncRNA biology.

6) Carrying out more research on lncRNA-based therapy in vivo using optimal delivery systems.

\section{AUTHOR CONTRIBUTIONS}

All authors listed have made a substantial, direct and intellectual contribution to the work, and approved it for publication.

\section{FUNDING}

This work was supported by the National Natural Science Foundation of China (81372039 and 81971810), Liaoning Science Project (2018108001 and 2017225003), and Shengjing Hospital 345 Talent Project. 


\section{REFERENCES}

1. Thum T. Facts and updates about cardiovascular non-coding RNAs in heart failure. ESC Heart Fail. (2015) 2:108-11. doi: 10.1002/ehf2.12054

2. Zhang TN, Goodwin JE, Liu B, Li D, Wen $\mathrm{R}$, Yang $\mathrm{N}$, et al. Characterization of long noncoding RNA and mRNA profiles in sepsisinduced myocardial depression. Mol Ther Nucleic Acids. (2019) 17:852-66. doi: 10.1016/j.omtn.2019.07.020

3. Jiao J, Shi B, Wang T, Fang Y, Cao T, Zhou Y, et al. Characterization of long non-coding RNA and messenger RNA profiles in follicular fluid from mature and immature ovarian follicles of healthy women and women with polycystic ovary syndrome. Hum Reprod. (2018) 33:1735-48. doi: 10.1093/humrep/dey255

4. Muret K, Désert C, Lagoutte L, Boutin M, Gondret F, Zerjal T, et al. Long noncoding RNAs in lipid metabolism: literature review and conservation analysis across species. BMC Genomics. (2019) 20:882. doi: 10.1186/s12864-019-6093-3

5. Liu H, Luo J, Luan S, He C, Li Z. Long non-coding RNAs involved in cancer metabolic reprogramming. Cell Mol Life Sci. (2019) 76:495-504. doi: 10.1007/s00018-018-2946-1

6. Mulukutla BC, Yongky A, Le T, Mashek DG, Hu WS. Regulation of glucose metabolism - a perspective from cell bioprocessing. Trends Biotechnol. (2016) 34:638-51. doi: 10.1016/j.tibtech.2016.04.012

7. Li Z, Zhang H. Reprogramming of glucose, fatty acid and amino acid metabolism for cancer progression. Cell Mol Life Sci. (2016) 73:377-92. doi: 10.1007/s00018-015-2070-4

8. Libby P, Ridker PM, Hansson GK. Progress and challenges in translating the biology of atherosclerosis. Nature. (2011) 473:317-25. doi: 10.1038/nature10146

9. Cabili MN, Trapnell C, Goff L, Koziol M, Tazon-Vega B, Regev A, et al. Integrative annotation of human large intergenic noncoding RNAs reveals global properties and specific subclasses. Genes Dev. (2011) 25:1915-27. doi: $10.1101 / \operatorname{gad} .17446611$

10. Rinn JL, Chang HY. Genome regulation by long noncoding RNAs. Annu Rev Biochem. (2012) 81:145-66. doi: 10.1146/annurev-biochem-051410-092902

11. Zeng Y, Ren K, Zhu X, Zheng Z, Yi G. Long noncoding RNAs: advances in lipid metabolism. Adv Clin Chem. (2018) 87:1-36. doi: 10.1016/bs.acc.2018.07.001

12. Guttman M, Rinn JL. Modular regulatory principles of large non-coding RNAs. Nature. (2012) 482:339-46. doi: 10.1038/nature10887

13. Boon RA, Jaé N, Holdt L, Dimmeler S. Long noncoding RNAs: from clinical genetics to therapeutic targets? J Am College Cardiol. (2016) 67:1214-26. doi: 10.1016/j.jacc.2015.12.051

14. Chen LL. Linking long noncoding RNA localization and function. Trends Biochem Sci. (2016) 41:761-72. doi: 10.1016/j.tibs.2016.07.003

15. Xiang JF, Yin QF, Chen T, Zhang Y, Zhang XO, Wu Z, et al. Human colorectal cancer-specific CCAT1-L lncRNA regulates long-range chromatin interactions at the MYC locus. Cell Res. (2014) 24:513-31. doi: $10.1038 / \mathrm{cr} .2014 .35$

16. Yin QF, Yang L, Zhang Y, Xiang JF, Wu YW, Carmichael GG, et al. Long noncoding RNAs with snoRNA ends. Mol Cell. (2012) 48:219-30. doi: 10.1016/j.molcel.2012.07.033

17. Gupta RA, Shah N, Wang KC, Kim J, Horlings HM, Wong DJ, et al. Long non-coding RNA HOTAIR reprograms chromatin state to promote cancer metastasis. Nature. (2010) 464:1071-6. doi: 10.1038/nature08975

18. Liu B, Sun L, Liu Q, Gong C, Yao Y, Lv X, et al. A cytoplasmic NF- $\kappa$ B interacting long noncoding RNA blocks I $\mathrm{KB}$ phosphorylation and suppresses breast cancer metastasis. Cancer Cell. (2015) 27:370-81. doi: 10.1016/j.ccell.2015.02.004

19. Cesana M, Cacchiarelli D, Legnini I, Santini T, Sthandier O, Chinappi $\mathrm{M}$, et al. A long noncoding RNA controls muscle differentiation by functioning as a competing endogenous RNA. Cell. (2011) 147:358-69. doi: 10.1016/j.cell.2011.09.028

20. Lee S, Kopp F, Chang TC, Sataluri A, Chen B, Sivakumar S, et al. Noncoding RNA NORAD regulates genomic stability by sequestering PUMILIO proteins. Cell. (2016) 164:69-80. doi: 10.1016/j.cell.2015. 12.017
21. Yoon JH, Abdelmohsen K, Srikantan S, Yang X, Martindale JL, De S, et al. LincRNA-p21 suppresses target mRNA translation. Mol Cell. (2012) 47:648-55. doi: 10.1016/j.molcel.2012.06.027

22. Zhang Y, Xu N, Xu J, Kong B, Copple B, Guo GL, et al. E2F1 is a novel fibrogenic gene that regulates cholestatic liver fibrosis through the Egr1/SHP/EID1 network. Hepatology. (2014) 60:919-30. doi: 10.1002/hep.27121

23. Nolan CJ, Prentki M. The islet beta-cell: fuel responsive and vulnerable. Trends Endocrinol Metab. (2008) 19:285-91. doi: 10.1016/j.tem.2008.07.006

24. Ku GM, Kim H, Vaughn IW, Hangauer MJ, Myung Oh C, German MS, et al. Research resource: RNA-Seq reveals unique features of the pancreatic $\beta$-cell transcriptome. Mol Endocrinol. (2012) 26:1783-92. doi: 10.1210/me.2012-1176

25. Morán I, Akerman I, van de Bunt M, Xie R, Benazra M, Nammo T, et al. Human $\beta$ cell transcriptome analysis uncovers lncRNAs that are tissuespecific, dynamically regulated, and abnormally expressed in type 2 diabetes. Cell Metab. (2012) 16:435-48. doi: 10.1016/j.cmet.2012.08.010

26. Arnes L, Sussel L. Epigenetic modifications and long noncoding RNAs influence pancreas development and function. Trends Genet. (2015) 31:2909. doi: 10.1016/j.tig.2015.02.008

27. Sanchez-Parra C, Jacovetti C, Dumortier O, Lee K, Peyot ML, Guay $\mathrm{C}$, et al. Contribution of the long noncoding RNA H19 to $\beta$-cell mass expansion in neonatal and adult rodents. Diabetes. (2018) 67:2254-67. doi: $10.2337 / \mathrm{db} 18-0201$

28. Arnes L, Akerman I, Balderes DA, Ferrer J, Sussel L. $\beta$ linc1 encodes a long noncoding RNA that regulates islet $\beta$-cell formation and function. Genes Dev. (2016) 30:502-7. doi: 10.1101/gad.273821.115

29. Wang N, Zhu Y, Xie M, Wang L, Jin F, Li Y, et al. Long noncoding RNA meg3 regulates mafa expression in mouse beta cells by inactivating Rad21, Smc3 or Sin3 $\alpha$. Cell Physiol Biochem. (2018) 45:2031-43. doi: 10.1159/000487983

30. Zhao X, Rong C, Pan F, Xiang L, Wang X, Hu Y. Expression characteristics of long noncoding RNA uc.322 and its effects on pancreatic islet function. $J$ Cell Biochem. (2018) 119:9239-48. doi: 10.1002/jcb.27191

31. You L, Wang N, Yin D, Wang L, Jin F, Zhu Y, et al. Downregulation of long noncoding RNA Meg3 affects insulin synthesis and secretion in mouse pancreatic beta cells. J Cell Physiol. (2016) 231:852-62. doi: $10.1002 /$ jcp. 25175

32. Yin DD, Zhang EB, You LH, Wang N, Wang LT, Jin FY, et al. Downregulation of lncRNA TUG1 affects apoptosis and insulin secretion in mouse pancreatic $\beta$ cells. Cell Physiol Biochem. (2015) 35:1892-904. doi: 10.1159/000373999

33. Ruan X, Li P, Cangelosi A, Yang L, Cao H. A long non-coding RNA, lncLGR, regulates hepatic glucokinase expression and glycogen storage during fasting. Cell Rep. (2016) 14:1867-75. doi: 10.1016/j.celrep.2016.01.062

34. Xu B, Gerin I, Miao H, Vu-Phan D, Johnson CN, Xu R, et al. Multiple roles for the non-coding RNA SRA in regulation of adipogenesis and insulin sensitivity. PLoS ONE. (2010) 5:e14199. doi: 10.1371/journal.pone.0014199

35. Liu S, Sheng L, Miao H, Saunders TL, MacDougald OA, Koenig RJ, et al. SRA gene knockout protects against diet-induced obesity and improves glucose tolerance. J Biol Chem. (2014) 289:13000-9. doi: 10.1074/jbc.M114.564658

36. Zhang P, Bai H, Li J, Liu J, Ma W, Xu B, et al. Knockdown of slincRAD leads to defective adipose development in vivo. Biochem Biophys Res Commun. (2019) 513:983-9. doi: 10.1016/j.bbrc.2019.04.035

37. Takahashi N, Kimura AP, Otsuka K, Ohmura K, Naito S, Yoshida M, et al. Dreh, a long noncoding RNA repressed by metformin, regulates glucose transport in C2C12 skeletal muscle cells. Life Sci. (2019) 236:116906. doi: 10.1016/j.lfs.2019.116906

38. Geng T, Liu Y, Xu Y, Jiang Y, Zhang N, Wang Z, et al. H19 lncRNA promotes skeletal muscle insulin sensitivity in part by targeting AMPK. Diabetes. (2018) 67:2183-98. doi: 10.2337/db18-0370

39. Magnusson I, Rothman DL, Katz LD, Shulman RG, Shulman GI. Increased rate of gluconeogenesis in type II diabetes mellitus. A 13C nuclear magnetic resonance study. J Clin Invest. (1992) 90:1323-7. doi: 10.1172/JCI115997

40. Oh KJ, Han HS, Kim MJ, Koo SH. CREB and FoxO1: two transcription factors for the regulation of hepatic gluconeogenesis. BMB Rep. (2013) 46:567-74. doi: 10.5483/BMBRep.2013.46.12.248

41. Yoon JC, Puigserver P, Chen G, Donovan J, Wu Z, Rhee J, et al. Control of hepatic gluconeogenesis through the transcriptional coactivator PGC-1. Nature. (2001) 413:131-8. doi: 10.1038/35093050 
42. Goyal N, Tiwary S, Kesharwani D, Datta M. Long non-coding RNA H19 inhibition promotes hyperglycemia in mice by upregulating hepatic FoxO1 levels and promoting gluconeogenesis. J Mol Med. (2019) 97:115-26. doi: 10.1007/s00109-018-1718-6

43. Goyal N, Sivadas A, Shamsudheen KV, Jayarajan R, Verma A, Sivasubbu $\mathrm{S}$, et al. RNA sequencing of $\mathrm{db} / \mathrm{db}$ mice liver identifies lncRNA H19 as a key regulator of gluconeogenesis and hepatic glucose output. Sci Rep. (2017) 7:8312. doi: 10.1038/s41598-017-08281-7

44. Zhang N, Geng T, Wang Z, Zhang R, Cao T, Camporez JP, et al. Elevated hepatic expression of $\mathrm{H} 19$ long noncoding RNA contributes to diabetic hyperglycemia. JCI Insight. (2018) 3:e120304. doi: 10.1172/jci.insight.120304

45. Zhu X, Wu YB, Zhou J, Kang DM. Upregulation of lncRNA MEG3 promotes hepatic insulin resistance via increasing FoxO1 expression. Biochem Biophys Res Commun. (2016) 469:319-25. doi: 10.1016/j.bbrc.2015.11.048

46. Zhu X, Li H, Wu Y, Zhou J, Yang G, Wang W. lncRNA MEG3 promotes hepatic insulin resistance by serving as a competing endogenous RNA of miR-214 to regulate ATF4 expression. Int J Mol Med. (2019) 43:345-57. doi: 10.3892/ijmm.2018.3975

47. Yan C, Li J, Feng S, Li Y, Tan L. Long noncoding RNA gomafu upregulates Foxol expression to promote hepatic insulin resistance by sponging miR139-5p. Cell Death Dis. (2018) 9:289. doi: 10.1038/s41419-018-0321-7

48. Cui X, Tan J, Shi Y, Sun C, Li Y, Ji C, et al. The long non-coding RNA Gm10768 activates hepatic gluconeogenesis by sequestering microRNA-214 in mice. J Biol Chem. (2018) 293:4097-109. doi: 10.1074/jbc.M117.812818

49. Song M, Zou L, Peng L, Liu S, Wu B, Yi Z, et al. LncRNA NONRATT021972 siRNA normalized the dysfunction of hepatic glucokinase through AKT signaling in T2DM rats. Endocr Res. (2017) 42:180-90. doi: 10.1080/07435800.2017.1292522

50. Luo F, Liu X, Ling M, Lu L, Shi L, Lu X, et al. The lncRNA MALAT1, acting through HIF- $1 \alpha$ stabilization, enhances arsenite-induced glycolysis in human hepatic L-02 cells. Biochim Biophys Acta. (2016) 1862:1685-95. doi: 10.1016/j.bbadis.2016.06.004

51. Han M, You L, Wu Y, Gu N, Wang Y, Feng X, et al. RNA-sequencing analysis reveals the potential contribution of IncRNAs in palmitic acid-induced insulin resistance of skeletal muscle cells. Biosci Rep. (2020) 40:BSR20192523. doi: 10.1042/BSR20192523

52. Zhang N, Zhou Y, Yuan Q, Gao Y, Wang Y, Wang X, et al. Dynamic transcriptome profile in $\mathrm{db} / \mathrm{db}$ skeletal muscle reveal critical roles for long noncoding RNA regulator. Int J Biochem Cell Biol. (2018) 104:14-24. doi: 10.1016/j.biocel.2018.08.013

53. Yang L, Wang X, Guo H, Zhang W, Wang W, Ma H. Whole transcriptome analysis of obese adipose tissue suggests $\mathrm{u} 001 \mathrm{kfc} .1$ as a potential regulator to glucose homeostasis. Front Genet. (2019) 10:1133. doi: 10.3389/fgene.2019.01133

54. Huang J, Chen S, Cai D, Bian D, Wang F. Long noncoding RNA lncARSR promotes hepatic cholesterol biosynthesis via modulating Akt/SREBP2/HMGCR pathway. Life Sci. (2018) 203:48-53. doi: 10.1016/j.lfs.2018.04.028

55. Sallam T, Jones MC, Gilliland T, Zhang L, Wu X, Eskin A, et al. Feedback modulation of cholesterol metabolism by the lipid-responsive non-coding RNA LeXis. Nature. (2016) 534:124-8. doi: 10.1038/nature17674

56. Liu G, Zheng X, Xu Y, Lu J, Chen J, Huang X. Long non-coding RNAs expression profile in HepG2 cells reveals the potential role of long noncoding RNAs in the cholesterol metabolism. Chinese Med J. (2015) 128:91-7. doi: 10.4103/0366-6999.147824

57. Liu C, Yang Z, Wu J, Zhang L, Lee S, Shin DJ, et al. Long noncoding RNA H19 interacts with polypyrimidine tract-binding protein 1 to reprogram hepatic lipid homeostasis. Hepatology. (2018) 67:1768-83. doi: 10.1002/hep.29654

58. Zhao XY, Xiong X, Liu T, Mi L, Peng X, Rui C, et al. Long noncoding RNA licensing of obesity-linked hepatic lipogenesis and NAFLD pathogenesis. Nat Commun. (2018) 9:2986. doi: 10.1038/s41467-018-05383-2

59. Yan C, Chen J, Chen N. Long noncoding RNA MALAT1 promotes hepatic steatosis and insulin resistance by increasing nuclear SREBP-1c protein stability. Sci Rep. (2016) 6:22640. doi: 10.1038/srep22640

60. Dong Z, Li C, Yin C, Xu M, Liu S, Gao M. LncRNA PU.1 AS regulates arsenic-induced lipid metabolism through EZH2/Sirt6/SREBP1c pathway. J Environ Sci. (2019) 85:138-146. doi: 10.1016/j.jes.2019. 05.019
61. Li D, Cheng M, Niu Y, Chi X, Liu X, Fan J, et al. Identification of a novel human long non-coding RNA that regulates hepatic lipid metabolism by inhibiting SREBP-1c. Int J Biol Sci. (2017) 13:349-57. doi: 10.7150/ijbs.16635

62. Lan X, Wu L, Wu N, Chen Q, Li Y, Du X, et al. Long noncoding RNA lnc-HC regulates $\operatorname{PPAR} \gamma$-mediated hepatic lipid metabolism through miR-130b-3p. Mol Ther Nucleic Acids. (2019) 18:954-65. doi: 10.1016/j.omtn.2019.10.018

63. Hu YW, Yang JY, Ma X, Chen ZP, Hu YR, Zhao JY, et al. A lincRNADYNLRB2-2/GPR119/GLP-1R/ABCA1-dependent signal transduction pathway is essential for the regulation of cholesterol homeostasis. J Llipid Res. (2014) 55:681-97. doi: 10.1194/jlr.M044669

64. Sallam T, Jones M, Thomas BJ, Wu X, Gilliland T, Qian K, et al. Transcriptional regulation of macrophage cholesterol efflux atherogenesis by a long noncoding RNA. Nat Med. (2018) 24:304-12. doi: 10.1038/nm.4479

65. Lan X, Yan J, Ren J, Zhong B, Li J, Li Y, et al. A novel long noncoding RNA Lnc-HC binds hnRNPA2B1 to regulate expressions of Cyp7a1 and Abcal in hepatocytic cholesterol metabolism. Hepatology. (2016) 64:58-72. doi: 10.1002/hep. 28391

66. Meng XD, Yao HH, Wang LM, Yu M, Shi S, Yuan ZX, et al. Knockdown of GAS5 inhibits atherosclerosis progression via reducing EZH2-mediated ABCA1 transcription in ApoE(-/-) Mice. Mol Ther Nucl Acids. (2020) 19:84-96. doi: 10.1016/j.omtn.2019.10.034

67. Hu YW, Zhao JY, Li SF, Huang JL, Qiu YR, Ma X, et al. RP5833A20.1/miR-382-5p/NFIA-dependent signal transduction pathway contributes to the regulation of cholesterol homeostasis and inflammatory reaction. Arterioscler Thromb Vasc Biol. (2015) 35:87-101. doi: 10.1161/ATVBAHA.114.304296

68. Halley P, Kadakkuzha BM, Faghihi MA, Magistri M, Zeier Z, Khorkova O, et al. Regulation of the apolipoprotein gene cluster by a long noncoding RNA. Cell Rep. (2014) 6:222-30. doi: 10.1016/j.celrep.2013.12.015

69. Qin W, Li X, Xie L, Li S, Liu J, Jia L, et al. A long non-coding RNA, APOA4AS, regulates APOA4 expression depending on HuR in mice. Nucleic Acids Res. (2016) 44:6423-33. doi: 10.1093/nar/gkw341

70. Ray RM, Hansen AH, Slott S, Taskova M, Astakhova K, Morris KV. Control of LDL uptake in human cells by targeting the LDLR regulatory long non-coding RNA BM450697. Mol Ther Nucl Acids. (2019) 17:264-76. doi: 10.1016/j.omtn.2019.05.024

71. Mitchel K, Theusch E, Cubitt C, Dosé AC, Stevens K, Naidoo $\mathrm{D}$, et al. RP1-13D10.2 is a novel modulator of statin-induced changes in cholesterol. Circ Cardiovasc Genet. (2016) 9:223-30. doi: 10.1161/CIRCGENETICS.115.001274

72. Wang L, Xia JW, Ke ZP, Zhang BH. Blockade of NEAT1 represses inflammation response and lipid uptake via modulating miR-342-3p in human macrophages THP-1 cells. J Cell Physiol. (2019) 234:5319-26. doi: 10.1002/jcp.27340

73. Li P, Ruan X, Yang L, Kiesewetter K, Zhao Y, Luo H, et al. A liver-enriched long non-coding RNA, lncLSTR, regulates systemic lipid metabolism in mice. Cell Metab. (2015) 21:455-67. doi: 10.1016/j.cmet.2015.02.004

74. Liu Y, Wang Y, He X, Zhang S, Wang K, Wu H, et al. LncRNA TINCR/miR$31-5 \mathrm{p} / \mathrm{C} / \mathrm{EBP}-\alpha$ feedback loop modulates the adipogenic differentiation process in human adipose tissue-derived mesenchymal stem cells. Stem Cell Res. (2018) 32:35-42. doi: 10.1016/j.scr.2018.08.016

75. Huang X, Fu C, Liu W, Liang Y, Li P, Liu Z, et al. Chemerin-induced angiogenesis and adipogenesis in $3 \mathrm{~T} 3-\mathrm{L} 1$ preadipocytes is mediated by lncRNA Meg3 through regulating Dickkopf-3 by sponging miR-217. Toxicol Appl Pharmacol. (2019) 385:114815. doi: 10.1016/j.taap.2019.114815

76. Pang WJ, Lin LG, Xiong Y, Wei N, Wang Y, Shen QW, et al. Knockdown of PU.1 AS lncRNA inhibits adipogenesis through enhancing PU.1 mRNA translation. J Cell Biochem. (2013) 114:2500-12. doi: 10.1002/jcb.24595

77. Shang G, Wang Y, Xu Y, Zhang S, Sun X, Guan H, et al. Long non-coding RNA TCONS_00041960 enhances osteogenesis and inhibits adipogenesis of rat bone marrow mesenchymal stem cell by targeting miR-204-5p and miR-125a-3p. J Cell Physiol. (2018) 233:6041-51. doi: 10.1002/jcp.26424

78. Liu H, Li H, Jin L, Li G, Hu S, Ning C, et al. Long noncoding RNA GAS5 suppresses 3T3-L1 cells adipogenesis through miR-21a-5p/PTEN signal pathway. DNA Cell Biol. (2018) 37:767-77. doi: 10.1089/dna.2018.4264

79. Cai R, Sun Y, Qimuge N, Wang G, Wang Y, Chu G, et al. Adiponectin AS lncRNA inhibits adipogenesis by transferring from nucleus to cytoplasm and 
attenuating Adiponectin mRNA translation. Biochim Biophys Acta Mol Cell Biol Lipids. (2018) 1863:420-32. doi: 10.1016/j.bbalip.2018.01.005

80. Schmidt E, Dhaouadi I, Gaziano I, Oliverio M, Klemm P, Awazawa $\mathrm{M}$, et al. LincRNA H19 protects from dietary obesity by constraining expression of monoallelic genes in brown fat. Nat Commun. (2018) 9:3622. doi: 10.1038/s41467-018-05933-8

81. Zhao XY, Li S, Wang GX, Yu Q, Lin JD. A long noncoding RNA transcriptional regulatory circuit drives thermogenic adipocyte differentiation. Mol Cell. (2014) 55:372-82. doi: 10.1016/j.molcel.2014.06.004

82. Mi L, Zhao XY, Li S, Yang G, Lin JD. Conserved function of the long noncoding RNA Blnc1 in brown adipocyte differentiation. Mol Metab. (2017) 6:101-110. doi: 10.1016/j.molmet.2016.10.010

83. Li S, Mi L, Yu L, Yu Q, Liu T, Wang GX, et al. Zbtb7b engages the long noncoding RNA Blncl to drive brown and beige fat development and thermogenesis. Proc Natl Acad Sci USA. (2017) 114:E7111-20. doi: 10.1073/pnas.1703494114

84. Alvarez-Dominguez JR, Bai Z, Xu D, Yuan B, Lo KA, Yoon MJ, et al. De Novo reconstruction of adipose tissue transcriptomes reveals long non-coding rna regulators of brown adipocyte development. Cell Metab. (2015) 21:764-76. doi: 10.1016/j.cmet.2015.04.003

85. Bai Z, Chai XR, Yoon MJ, Kim HJ, Lo KA, Zhang ZC, et al. Dynamic transcriptome changes during adipose tissue energy expenditure reveal critical roles for long noncoding RNA regulators. PLoS Biol. (2017) 15:e2002176. doi: 10.1371/journal.pbio.2002176

86. Cui X, You L, Li Y, Zhu L, Zhang F, Xie K, et al. A transcribed ultraconserved noncoding RNA, uc.417, serves as a negative regulator of brown adipose tissue thermogenesis. FASEB J. (2016) 30:4301-12. doi: 10.1096/fj.201600694R

87. Eberlé D, Hegarty B, Bossard P, Ferré P, Foufelle F. SREBP transcription factors: master regulators of lipid homeostasis. Biochimie. (2004) 86:839-48. doi: 10.1016/j.biochi.2004.09.018

88. Horton JD, Goldstein JL, Brown MS. SREBPs: activators of the complete program of cholesterol and fatty acid synthesis in the liver. J Clin Invest. (2002) 109:1125-31. doi: 10.1172/JCI0215593

89. Wang H, Cao Y, Shu L, Zhu Y, Peng Q, Ran L, et al. Long non-coding RNA (lncRNA) H19 induces hepatic steatosis through activating MLXIPL and mTORC1 networks in hepatocytes. J Cell Mol Med. (2020) 24:1399-412. doi: $10.1111 / \mathrm{jcmm} .14818$

90. Ye D, Lammers B, Zhao Y, Meurs I, Van Berkel TJ, van Eck M. ATP-binding cassette transporters Al and G1, HDL metabolism, cholesterol efflux, and inflammation: important targets for the treatment of atherosclerosis. Curr Drug Targets. (2011) 12:647-60. doi: 10.2174/1389450117953 78522

91. Xing Z, Zhang Y, Liang K, Yan L, Xiang Y, Li C, et al. Expression of long noncoding RNA YIYA promotes glycolysis in breast cancer. Cancer Res. (2018) 78:4524-32. doi: 10.1158/0008-5472.CAN-17-0385

92. Fadista J, Vikman P, Laakso EO, Mollet IG, Esguerra JL, Taneera J, et al. Global genomic and transcriptomic analysis of human pancreatic islets reveals novel genes influencing glucose metabolism. Proc Natl Acad Sci USA. (2014) 111:13924-29. doi: 10.1073/pnas.1402665111

93. Guo J, Fang W, Sun L, Lu Y, Dou L, Huang X, et al. Ultraconserved element uc.372 drives hepatic lipid accumulation by suppressing miR-195/miR4668 maturation. Nat Commun. (2018) 9:612. doi: 10.1038/s41467-018-03072-8

94. Goodwin B, Jones SA, Price RR, Watson MA, McKee DD, Moore $\mathrm{LB}$, et al. A regulatory cascade of the nuclear receptors FXR, SHP-1, and LRH-1 represses bile acid biosynthesis. Mol Cell. (2000) 6:517-26. doi: 10.1016/S1097-2765(00)00051-4

95. Qi R, Qiu X, Zhang Y, Wang J, Wang Q, Wu M, et al. Comparison of LncRNA expression profiles during myogenic differentiation and adipogenic transdifferentiation of myoblasts. Int J Mol Sci. (2019) 20:3725. doi: $10.3390 /$ ijms 20153725

96. Sun L, Goff LA, Trapnell C, Alexander R, Lo KA, Hacisuleyman E, et al. Long noncoding RNAs regulate adipogenesis. Proc Natl Acad Sci USA. (2013) 110:3387-92. doi: 10.1073/pnas.1222643110

97. Liu W, Ma C, Yang B, Yin C, Zhang B, Xiao Y. LncRNA Gm15290 sponges miR-27b to promote PPAR $\gamma$-induced fat deposition and contribute to body weight gain in mice. Biochem Biophys Res Commun. (2017) 493:1168-75. doi: 10.1016/j.bbrc.2017.09.114
98. Xiao T, Liu L, Li H, Sun Y, Luo H, Li T, et al. Long noncoding RNA ADINR regulates adipogenesis by transcriptionally activating C/EBP $\alpha$. Stem Cell Rep. (2015) 5:856-65. doi: 10.1016/j.stemcr.2015.09.007

99. Gernapudi R, Wolfson B, Zhang Y, Yao Y, Yang P, Asahara H, et al. MicroRNA 140 promotes expression of long noncoding RNA NEAT1 in adipogenesis. Mol Cell Biol. (2016) 36:30-8. doi: 10.1128/MCB.00702-15

100. Firmin FF, Oger F, Gheeraert C, Dubois-Chevalier J, Vercoutter-Edouart AS, Alzaid F, et al. The RBM14/CoAA-interacting, long intergenic non-coding RNA Parall regulates adipogenesis and coactivates the nuclear receptor

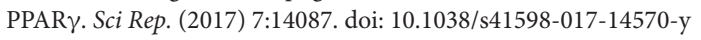

101. Chen J, Liu Y, Lu S, Yin L, Zong C, Cui S, et al. The role and possible mechanism of IncRNA U90926 in modulating 3T3-L1 preadipocyte differentiation. Int J Obes. (2017) 41:299-308. doi: 10.1038/ijo.2016.189

102. Li M, Gao Q, Tian Z, Lu X, Sun Y, Chen Z, et al. MIR221HG is a novel long noncoding RNA that inhibits bovine adipocyte differentiation. Genes. (2019) 11:29. doi: 10.3390/genes11010029

103. Liu Y, Ji Y, Li M, Wang M, Yi X, Yin C, et al. Integrated analysis of long noncoding RNA and mRNA expression profile in children with obesity by microarray analysis. Sci Rep. (2018) 8:8750. doi: 10.1038/s41598-018-27113-w

104. Farmer SR. Transcriptional control of adipocyte formation. Cell Metab. (2006) 4:263-73. doi: 10.1016/j.cmet.2006.07.001

105. Wu J, Cohen P, Spiegelman BM. Adaptive thermogenesis in adipocytes: is beige the new brown? Genes Dev. (2013) 27:234-50. doi: $10.1101 /$ gad.211649.112

106. Ding C, Lim YC, Chia SY, Walet ACE, Xu S, Lo KA, et al. De novo reconstruction of human adipose transcriptome reveals conserved lncRNAs as regulators of brown adipogenesis. Nat Commun. (2018) 9:1329. doi: 10.1038/s41467-018-03754-3

107. You L, Zhou Y, Cui X, Wang X, Sun Y, Gao Y, et al. GM13133 is a negative regulator in mouse white adipocytes differentiation and drives the characteristics of brown adipocytes. J Cell Physiol. (2018) 233:313-24. doi: $10.1002 /$ jcp. 25878

108. Siegel RL, Miller KD, Jemal A. Cancer statistics, 2020. CA Cancer J Clin. (2020) 70:7-30. doi: $10.3322 /$ caac. 21590

109. Zheng YL, Li L, Jia YX, Zhang BZ, Li JC, Zhu YH, et al. LINC01554mediated glucose metabolism reprogramming suppresses tumorigenicity in hepatocellular carcinoma via downregulating PKM2 expression and inhibiting Akt/mTOR signaling pathway. Theranostics. (2019) 9:796-810. doi: $10.7150 /$ thno. 28992

110. Malakar P, Stein I, Saragovi A, Winkler R, Stern-Ginossar N, Berger M, et al. Long noncoding RNA MALAT1 regulates cancer glucose metabolism by enhancing mTOR-mediated translation of TCF7L2. Cancer Res. (2019) 79:2480-93. doi: 10.1158/0008-5472.CAN-18-1432

111. Tang J, Yan T, Bao Y, Shen C, Yu C, Zhu X, et al. LncRNA GLCC1 promotes colorectal carcinogenesis and glucose metabolism by stabilizing c-Myc. Nat Commun. (2019) 10:3499. doi: 10.1038/s41467-019-11447-8

112. Feng J, Ma J, Liu S, Wang J, Chen Y. A noncoding RNA LINC00504 interacts with c-Myc to regulate tumor metabolism in colon cancer. J Cell Biochem. (2019) 120:14725-34. doi: 10.1002/jcb.28733

113. Li W, Huang K, Wen F, Cui G, Guo H, He Z, et al. LINC00184 silencing inhibits glycolysis and restores mitochondrial oxidative phosphorylation in esophageal cancer through demethylation of PTEN. EBiomedicine. (2019) 44:298-310. doi: 10.1016/j.ebiom.2019.05.055

114. Ma Y, Hu M, Zhou L, Ling S, Li Y, Kong B, et al. Long non-coding RNA HOTAIR promotes cancer cell energy metabolism in pancreatic adenocarcinoma by upregulating hexokinase-2. Oncol Lett. (2019) 18:22129. doi: 10.3892/ol.2019.10551

115. Chen S, Xu X, Lu S, Hu B. Long non-coding RNA HAND2-AS1 targets glucose metabolism and inhibits cancer cell proliferation in osteosarcoma. Oncol Lett. (2019) 18:1323-9. doi: 10.3892/ol.2019.10445

116. Chu H, Li Z, Gan Z, Yang Z, Wu Z, Rong M. LncRNA ELF3-AS1 is involved in the regulation of oral squamous cell carcinoma cell proliferation by reprogramming glucose metabolism. OncoTargets Ther. (2019) 12:6857-63. doi: $10.2147 / O T T . S 217473$

117. Cheng Z, Luo C, Guo Z. LncRNA-XIST/microRNA-126 sponge mediates cell proliferation and glucose metabolism through the IRS1/PI3K/Akt pathway in glioma. J Cell Biochem. (2020) 121:2170-83. doi: 10.1002/jcb.29440 
118. Li X, Zhao Q, Qi J, Wang W, Zhang D, Li Z, et al. IncRNA Ftx promotes aerobic glycolysis and tumor progression through the PPAR $\gamma$ pathway in hepatocellular carcinoma. Int J Oncol. (2018) 53:551-66. doi: $10.3892 /$ ijo. 2018.4418

119. Kang Y, Zhu X, Xu Y, Tang Q, Huang Z, Zhao Z, et al. Energy stress-induced lncRNA HAND2-AS1 represses HIF1 $\alpha$-mediated energy metabolism and inhibits osteosarcoma progression. Am J Cancer Res. (2018) 8:526-37.

120. Han X, Yang Y, Sun Y, Qin L, Yang Y. LncRNA TUG1 affects cell viability by regulating glycolysis in osteosarcoma cells. Gene. (2018) 674:87-92. doi: 10.1016/j.gene.2018.06.085

121. Sun LY, Li XJ, Sun YM, Huang W, Fang K, Han C, et al. LncRNA ANRIL regulates AML development through modulating the glucose metabolism pathway of AdipoR1/AMPK/SIRT1. Mol Cancer. (2018) 17:127. doi: 10.1186/s12943-018-0879-9

122. Zhang Y, Liu Y, Xu X. Knockdown of LncRNA-UCA1 suppresses chemoresistance of pediatric AML by inhibiting glycolysis through the microRNA-125a/hexokinase 2 pathway. J Cell Biochem. (2018) 119:6296308. doi: $10.1002 /$ jcb. 26899

123. Yang X, Ye H, He M, Zhou X, Sun N, Guo W, et al. LncRNA PDIA3P interacts with c-Myc to regulate cell proliferation via induction of pentose phosphate pathway in multiple myeloma. Biochem Biophys Res Commun. (2018) 498:207-13. doi: 10.1016/j.bbrc.2018.02.211

124. Wang Y, Zhang X, Wang Z, Hu Q, Wu J, Li Y, et al. LncRNA-p23154 promotes the invasion-metastasis potential of oral squamous cell carcinoma by regulating Glut1-mediated glycolysis. Cancer Lett. (2018) 434:172-83. doi: 10.1016/j.canlet.2018.07.016

125. Luan W, Zhou Z, Ni X, Xia Y, Wang J, Yan Y, et al. Long non-coding RNA H19 promotes glucose metabolism and cell growth in malignant melanoma via miR-106a-5p/E2F3 axis. J Cancer Res Clin Oncol. (2018) 144:531-42. doi: $10.1007 / \mathrm{s} 00432-018-2582-\mathrm{z}$

126. Wei S, Fan Q, Yang L, Zhang X, Ma Y, Zong Z, et al. Promotion of glycolysis by HOTAIR through GLUT1 upregulation via mTOR signaling. Oncol Rep. (2017) 38:1902-8. doi: 10.3892/or.2017.5840

127. Song J, Wu X, Liu F, Li M, Sun Y, Wang Y, et al. Long non-coding RNA PVT1 promotes glycolysis and tumor progression by regulating miR-497/HK2 axis in osteosarcoma. Biochem Biophys Res Commun. (2017) 490:217-24. doi: 10.1016/j.bbrc.2017.06.024

128. Hu R, Zhong P, Xiong L, Duan L. Long noncoding RNA cancer susceptibility candidate 8 suppresses the proliferation of bladder cancer cells via regulating glycolysis. DNA Cell Biol. (2017) 36:767-74. doi: 10.1089/dna.2017.3785

129. Rupaimoole R, Lee J, Haemmerle M, Ling H, Previs RA, Pradeep S, et al. Long noncoding RNA Ceruloplasmin promotes cancer growth by altering glycolysis. Cell Rep. (2015) 13:2395-402. doi: 10.1016/j.celrep.2015.11.047

130. Li Z, Li X, Wu S, Xue M, Chen W. Long non-coding RNA UCA1 promotes glycolysis by upregulating hexokinase 2 through the mTOR-STAT3/microRNA143 pathway. Cancer Sci. (2014) 105:951-5. doi: $10.1111 /$ cas. 12461

131. Sim HW, Knox J. Hepatocellular carcinoma in the era of immunotherapy. Curr Prob Cancer. (2018) 42:40-8. doi: 10.1016/j.currproblcancer.2017.10.007

132. Park JW, Chen M, Colombo M, Roberts LR, Schwartz M, Chen PJ, et al. Global patterns of hepatocellular carcinoma management from diagnosis to death: the BRIDGE Study. Liver Int. (2015) 35:2155-66. doi: $10.1111 /$ liv. 12818

133. Brody H. Colorectal cancer. Nature. (2015) 521:S1. doi: 10.1038/521S1a

134. Isakoff MS, Bielack SS, Meltzer P, Gorlick R. Osteosarcoma: current treatment and a collaborative pathway to success. J Clin Oncol. (2015) 33:3029-35. doi: 10.1200/JCO.2014.59.4895

135. Yang $\mathrm{C}, \mathrm{Li} \mathrm{X}$, Wang $\mathrm{Y}$, Zhao L, Chen W. Long non-coding RNA UCA1 regulated cell cycle distribution via CREB through PI3-K dependent pathway in bladder carcinoma cells. Gene. (2012) 496:8-16. doi: 10.1016/j.gene.2012.01.012

136. Wang Y, Chen W, Yang C, Wu W, Wu S, Qin X, et al. Long non-coding RNA UCA1a(CUDR) promotes proliferation and tumorigenesis of bladder cancer. Int J Oncol. (2012) 41:276-84. doi: 10.3892/ijo.2012.1443

137. De Kouchkovsky I, Abdul-Hay M. Acute myeloid leukemia: a comprehensive review and 2016 update. Blood Cancer J. (2016) 6:e441. doi: $10.1038 /$ bcj. 2016.50
138. Shi J, Dai R, Chen Y, Guo H, Han Y, Zhang Y. LncRNA LINP1 regulates acute myeloid leukemia progression via HNF4a/AMPK/WNT5A signaling pathway. Hematol Oncol. (2019) 37:474-82. doi: 10.1002/hon.2651

139. Gong N, Teng X, Li J, Liang XJ. Antisense oligonucleotide-conjugated nanostructure-targeting lncRNA MALAT1 inhibits cancer metastasis. ACS Appl Mater Interfaces. (2019) 11:37-42. doi: 10.1021/acsami.8b18288

140. Gutschner T, Hämmerle M, Eissmann M, Hsu J, Kim Y, Hung G, et al. The noncoding RNA MALAT1 is a critical regulator of the metastasis phenotype of lung cancer cells. Cancer Res. (2013) 73:1180-9. doi: 10.1158/0008-5472.CAN-12-2850

141. Akerman I, Tu Z, Beucher A, Rolando DMY, Sauty-Colace C, Benazra $\mathrm{M}$, et al. Human pancreatic $\beta$ cell lncRNAs control cell-specific regulatory networks. Cell Metab. (2017) 25:400-11. doi: 10.1016/j.cmet.2016.11.016

142. Gao Y, Wu F, Zhou J, Yan L, Jurczak MJ, Lee HY, et al. The H19/let-7 doublenegative feedback loop contributes to glucose metabolism in muscle cells. Nucleic Acids Res. (2014) 42:13799-811. doi: 10.1093/nar/gku1160

143. Herder C, Kowall B, Tabak AG, Rathmann W. The potential of novel biomarkers to improve risk prediction of type 2 diabetes. Diabetologia. (2014) 57:16-29. doi: 10.1007/s00125-013-3061-3

144. Saeidi L, Ghaedi H, Sadatamini M, Vahabpour R, Rahimipour A, Shanaki $M$, et al. Long non-coding RNA LY86-AS1 and HCG27_201 expression in type 2 diabetes mellitus. Mol Biol Rep. (2018) 45:2601-8. doi: 10.1007/s11033-018-4429-8

145. Sathishkumar C, Prabu P, Mohan V, Balasubramanyam M. Linking a role of IncRNAs (long non-coding RNAs) with insulin resistance, accelerated senescence, and inflammation in patients with type 2 diabetes. Hum Genomics. (2018) 12:41. doi: 10.1186/s40246-018-0173-3

146. Zhang W, Zheng J, Hu X, Chen L. Dysregulated expression of long noncoding RNAs serves as diagnostic biomarkers of type 2 diabetes mellitus. Endocrine. (2019) 65:494-503. doi: 10.1007/s12020-019-02015-7

147. Catalano PM. Trying to understand gestational diabetes. Diabetic Med. (2014) 31:273-81. doi: 10.1111/dme.12381

148. Wang Q, Lu X, Li C, Zhang W, Lv Y, Wang L, et al. Down-regulated long non-coding RNA PVT1 contributes to gestational diabetes mellitus and preeclampsia via regulation of human trophoblast cells. Biomed Pharmacother Biomed Pharmacother. (2019) 120:109501. doi: 10.1016/j.biopha.2019.109501

149. Zhang $\mathrm{Y}, \mathrm{Wu} \mathrm{H}$, Wang F, Ye M, Zhu H, Bu S. Long non-coding RNA MALAT1 expression in patients with gestational diabetes mellitus. Int $J$ Gynaecol Obstetr. (2018) 140:164-9. doi: 10.1002/ijgo.12384

150. Hu D, Miao W, Chen T, Xie K, Shi A, Zhang L, et al. Genetic variants in AC092159.2 and risk of gestational diabetes mellitus in a Chinese population. DNA Cell Biol. (2019) 38:1069-77. doi: 10.1089/dna.2019.4827

151. Tao SC, Rui BY, Wang QY, Zhou D, Zhang Y, Guo SC. Extracellular vesiclemimetic nanovesicles transport LncRNA-H19 as competing endogenous RNA for the treatment of diabetic wounds. Drug Deliv. (2018) 25:241-55. doi: 10.1080/10717544.2018.1425774

152. Nuermaimaiti N, Liu J, Liang X, Jiao Y, Zhang D, Liu L, et al. Effect of IncRNA HOXA11-AS1 on adipocyte differentiation in human adiposederived stem cells. Biochem Biophys Res Commun. (2018) 495:1878-84. doi: 10.1016/j.bbrc.2017.12.006

153. Yuan Y, Cao X, Hu J, Li J, Shen D, You L, et al. The role and possible mechanism of lncRNA AC092159.2 in modulating adipocyte differentiation. J Mol Endocrinol. (2019) 62:137-48. doi: 10.1530/JME-18-0215

154. Pettinelli P, Del Pozo T, Araya J, Rodrigo R, Araya AV, Smok G, et al. Enhancement in liver SREBP-1c/PPAR-alpha ratio and steatosis in obese patients: correlations with insulin resistance and n-3 longchain polyunsaturated fatty acid depletion. Biochim Biophys Acta. (2009) 1792:1080-6. doi: 10.1016/j.bbadis.2009.08.015

155. Nabel EG, Braunwald E. A tale of coronary artery disease and myocardial infarction. N Engl J Med. (2012) 366:54-63. doi: 10.1056/NEJMra1112570

156. Vausort M, Wagner DR, Devaux Y. Long noncoding RNAs in patients with acute myocardial infarction. Circ Res. (2014) 115:668-77. doi: 10.1161/CIRCRESAHA.115.303836

157. Tontonoz P, Wu X, Jones M, Zhang Z, Salisbury D, Sallam T. Long noncoding RNA facilitated gene therapy reduces atherosclerosis in a murine model of familial hypercholesterolemia. Circulation. (2017) 136:776-8. doi: 10.1161/CIRCULATIONAHA.117.029002 
158. Toshikuni N, Tsutsumi M, Arisawa T. Clinical differences between alcoholic liver disease and nonalcoholic fatty liver disease. World J Gastroenterol. (2014) 20:8393-406. doi: 10.3748/wjg.v20.i26.8393

159. Sunny NE, Bril F, Cusi K. Mitochondrial adaptation in nonalcoholic fatty liver disease: novel mechanisms and treatment strategies. Trends Endocrinol Metab. (2017) 28:250-60. doi: 10.1016/j.tem.2016. 11.006

160. Tilg H, Moschen AR. Evolution of inflammation in nonalcoholic fatty liver disease: the multiple parallel hits hypothesis. Hepatology. (2010) 52:1836-46. doi: 10.1002/hep.24001

161. Wang J, Yang W, Chen Z, Chen J, Meng Y, Feng B, et al. Long noncoding RNA IncSHGL recruits hnRNPA1 to suppress hepatic gluconeogenesis and lipogenesis. Diabetes. (2018) 67:581-93. doi: 10.2337/db1 7-0799

162. Chen G, Yu D, Nian X, Liu J, Koenig RJ, Xu B, et al. LncRNA SRA promotes hepatic steatosis through repressing the expression of adipose triglyceride lipase (ATGL). Sci Rep. (2016) 6:35531. doi: 10.1038/srep 35531

163. Huang P, Huang FZ, Liu HZ, Zhang TY, Yang MS, Sun CZ. LncRNA MEG3 functions as a ceRNA in regulating hepatic lipogenesis by competitively binding to miR-21 with LRP6. Metab Clin Exp. (2019) 94:1-8. doi: 10.1016/j.metabol.2019.01.018

164. Sun C, Liu X, Yi Z, Xiao X, Yang M, Hu G, et al. Genome-wide analysis of long noncoding RNA expression profiles in patients with non-alcoholic fatty liver disease. IUBMB Life. (2015) 67:847-52. doi: 10.1002/iub.1442

165. Di Mauro S, Scamporrino A, Petta S, Urbano F, Filippello A, Ragusa M, et al. Serum coding and non-coding RNAs as biomarkers of NAFLD and fibrosis severity. Liver Int. (2019) 39:1742-54. doi: 10.1111/liv.14167

Conflict of Interest: The authors declare that the research was conducted in the absence of any commercial or financial relationships that could be construed as a potential conflict of interest.

Copyright (C) 2020 Zhang, Wang, Yang, Huang and Liu. This is an open-access article distributed under the terms of the Creative Commons Attribution License (CC BY). The use, distribution or reproduction in other forums is permitted, provided the original author(s) and the copyright owner(s) are credited and that the original publication in this journal is cited, in accordance with accepted academic practice. No use, distribution or reproduction is permitted which does not comply with these terms. 